\title{
1 TRF2-mediated ORC recruitment underlies telomere stability upon DNA replication stress
}

3 Mitsunori Higa, ${ }^{1}$ Yukihiro Matsuda, ${ }^{1}$ Jumpei Yamada, ${ }^{1}$ Nozomi Sugimoto, ${ }^{1}$ Kazumasa Yoshida,,${ }^{1 *}$ and

4 Masatoshi Fujita, ${ }^{1, *}$

$6{ }^{1}$ Department of Cellular Biochemistry, Graduate School of Pharmaceutical Sciences, Kyushu

7 University, 3-1-1 Maidashi, Higashi-ku, Fukuoka 812-8582, Japan

$9 *$ Correspondence to: Kazumasa Yoshida, Department of Cellular Biochemistry, Graduate School of 10 Pharmaceutical Sciences, Kyushu University, 3-1-1 Maidashi, Higashi-ku, Fukuoka 812-8582, Japan;

11 Tel: +81-92-642-6635; Fax: +81-92-642-6635; E-mail: kyoshida@phar.kyushu-u.ac.jp

13 *Correspondence to: Masatoshi Fujita, Department of Cellular Biochemistry, Graduate School of 14 Pharmaceutical Sciences, Kyushu University, 3-1-1 Maidashi, Higashi-ku, Fukuoka 812-8582, Japan; 15 Tel: +81-92-642-6635; Fax: +81-92-642-6635; E-mail: mfujita@phar.kyushu-u.ac.jp

17 Keywords: MCM /ORC / Replication stress / Telomere / TRF2

18 Running title: TRF2-ORC ensures telomere stability 


\section{Abstract}

2 Telomeres are intrinsically difficult-to-replicate regions of eukaryotic chromosomes. Telomeric

3 repeat binding factor 2 (TRF2) binds to origin recognition complex (ORC) to facilitate the loading of

4 ORC and the replicative helicase MCM complex onto DNA at telomeres. However, the biological

5 significance of the TRF2-ORC interaction for telomere maintenance remains largely elusive. Here,

6 we employed a separation-of-function TRF2 mutant with mutations in two acidic acid residues (E111A

7 and E112A) that specifically inhibited the TRF2-ORC interaction in human cells without substantially

8 inhibiting TRF2 interactions with its other binding partners. The TRF2 mutant was impaired in ORC

9 recruitment to telomeres and showed increased replication stress-associated telomeric DNA damage

10 and telomere instability. Furthermore, overexpression of an ORC1 fragment (amino acids 244-511),

11 which competitively inhibited the TRF2-ORC interaction, increased telomeric DNA damage under

12 replication stress conditions in human cells. Taken together, these findings suggest that TRF2-

13 mediated ORC recruitment contributes to the suppression of telomere instability. 


\section{Introduction}

2 The origin recognition complex (ORC) is composed of 6 subunits (ORC1-6) and binds to replication

3 origins distributed across the eukaryotic genome (Bleichert, 2019; Parker et al., 2017). Human ORC

4 binds to origin DNA with no obvious sequence specificity and binding principally depends on the

5 chromatin environment (Dellino et al., 2013; Higa et al., 2017a; Miotto et al., 2016; Parker et al., 2017;

6 Picard et al., 2014). ORC-binding sites share several common characteristics, such as the presence

7 of transcriptional start sites with an open chromatin structure, active histone modifications, and CpG islands (Dellino et al., 2013; Miotto et al., 2016; Picard et al., 2014). In addition, various chromatinassociated proteins, such as HP1 $\alpha$, dimethylated histone H4 (H4-K20me2), ORCA, and telomeric

10 repeat binding factor 2 (TRF2) (Higa et al., 2017a; Parker et al., 2017), associate with the ORC

11 complex and act as local ORC recruiters. In late $\mathrm{M}$ to $\mathrm{G} 1$ phase, $\mathrm{ORC}$, and the additional licensing

12 factors CDC6 and Cdt1, cooperatively promote the loading of minichromosome-maintenance (MCM)

13 complex, a core component of the replicative helicase (Bleichert, 2019; Parker et al., 2017; Sugimoto

14 and Fujita, 2017). During the following S phase, activated cyclin-dependent kinases (Cdks) and

15 Dbf4-dependent kinase (DDK) trigger the initiation of DNA replication. Phosphorylation of MCM

16 is a prerequisite for origin firing, while ORC, CDC6, and Cdt1 are downregulated by phosphorylation

17 to prevent MCM re-loading and DNA re-replication (Fujita, 2006; Hills and Diffley, 2014).

18 Replication stress-induced fork stalling activates MCMs pre-loaded onto dormant origins, promoting

19 origin firing to assist in the completion of replication. Reduction in MCM levels causes DNA breaks,

20 micronuclei formation, and genome instability, eventually leading to cellular senescence,

21 inflammation and increased cancer risk (Chuang et al., 2010; Ibarra et al., 2008; Kawabata et al., 2011;

22 Kunnev et al., 2010; McNairn et al., 2019; Sedlackova et al., 2020; Shima et al., 2007).

Telomeres are the terminal regions of linear chromosome. In mammals, the chromosome ends

24 form telomere loops (T-loops), protecting DNA ends from detection by DNA damage response sensors

25 (de Lange, 2018; Van Ly et al., 2018). End-protection is mostly achieved by telomere-specific 
chromatin-binding proteins that form the shelterin complex, comprised of TRF1, TRF2, RAP1, TIN2, TPP1, and POT1 (de Lange, 2018). DNA replication forks are prone to arrest and/or collapse at telomeres, leading to telomere instability, since telomeric higher-order structures and repetitive DNA sequences can interfere with fork progression (Gilson and Géli, 2007; Higa et al., 2017a; Martínez and Blasco, 2015; Pfeiffer and Lingner, 2013; Stroik and Hendrickson, 2020). In particular, guanine quadruplex (G4 DNA), DNA topological stress, and protective T-loop structures have been shown to lead to telomere instability if left unresolved during S phase (Fouché et al., 2006; Martínez et al., 2009; Sarek et al., 2015; Sfeir et al., 2009; Vannier et al., 2012). To facilitate telomere replication, the shelterin complex recruits additional factors to remove such obstacles during DNA replication. For example, TRF2 recruits Apollo, a nuclease that relieves topological stress (Chen et al., 2008; van

11 Overbeek and de Lange, 2006; Ye et al., 2010); RTEL1 helicase, which dismantles the G4 DNA and the T-loop structure (Sarek et al., 2019, 2015; Vannier et al., 2012); and SLX4, a multitasking protein

13 involved in the maintenance of telomere stability and the replication stress response (Guervilly and

14 Gaillard, 2018; Wan et al., 2013). Overall, a complicated protein network is required to achieve 15 efficient duplication of telomeric DNA tracts.

16 TRF2 is suggested to play a role in ORC and MCM loading at telomeres. TRF2 directly binds

17 to ORC through the ORC1 subunit (Atanasiu et al., 2006; Higa et al., 2017b; Tatsumi et al., 2008) and

18 RNA interference (RNAi)-mediated TRF2 silencing decreases loading of ORC and MCM onto

19 telomeric DNA (Deng et al., 2007; Tatsumi et al., 2008), suggesting that replication origins are 20 assembled at telomeres through the TRF2-ORC interaction. Indeed, DNA combing experiments have

21 demonstrated replication initiation events occurring inside the telomeric tract (Drosopoulos et al., 2020,

22 2015, 2012). These initiation events may play an important role in telomere maintenance as the

23 persistent arrest of replication forks within a telomere would otherwise result in under replication due

24 to the absence of a converging fork (Alver et al., 2014). Considering the inherent difficulties 25 associated with telomere replication, these telomeric replication origins may contribute to the complete 
1 duplication of telomeric tracts (Alver et al., 2014).

The biological role of the TRF2-ORC interaction is not fully understood, in part because siRNA-

3 mediated depletion of TRF2 or essential ORC subunits inevitably affects other fundamental functions

4 of these factors; for example, TRF2 knockdown affects telomere protection, while ORC1 knockdown

5 compromises genome-wide DNA replication licensing. In this study, we evaluated the biological

6 relevance of the TRF2-ORC interaction by two different means: firstly, by using a separation-of-

7 function TRF2 mutant defective only in ORC binding, we show that the TRF2-ORC interaction

8 promotes the recruitment of ORC and MCM at telomeres, and prevents telomere DNA damage and

9 telomere instability under DNA replication stress conditions; secondly, we demonstrate that

10 overexpression of an ORC1 fragment (amino acids 244-511), which binds to TRF2, competitively

11 inhibits ORC recruitment at telomeres and induces the replication stress-associated telomere DNA

12 damage in cells. These results strongly suggest that ORC recruitment by TRF2 underlies proficient

13 telomere replication and telomere stability. 


\section{Results}

TRF2 E111/E112 residues are required for efficient recruitment of ORC but not for interactions with other binding partners.

4 To evaluate the TRF2-ORC interaction we sought to identify a separation-of-function TRF2 mutant

5 defective only in its interaction with ORC. We previously reported that the dimerization of TRF2 is 6 required for the recruitment of ORC (Higa et al., 2017b). Using the lacO-LacI protein tethering assay

7 in U2OS 2-6-3 cells containing an array of 256 lacO repeats on chromosome 1 (Janicki et al., 2004), we have also shown that the TRFH (TRF homology) domain of TRF2 (amino acids 45-244) fused to LacI is sufficient for ORC and MCM recruitment to this lacO array (Higa et al., 2017b).

TRF2 V52D

10 and N53P mutations in the TRFH domain impairs TRF2 dimer formation and ORC recruitment by

11 TRF2 (Higa et al., 2017b). However, the TRF2 (V52D/N53P) mutant is not suitable as a specific

12 ORC interaction mutant because TRF2 dimerization is critical for its other functions, including

13 telomere binding. To identify a specific TRF2-ORC interaction mutant, residues predicted to be

14 required for binding to ORC1 were identified based on the crystal structure of the TRF2 TRFH domain

15 (PDB code 4M7C) and the previously published data described above (Figure 1A). TRF2 residues

16 were selected according to the following three criteria: (1) Since TRF2 dimerization is required for

17 ORC1 binding and recruitment, we speculated that ORC1 recognizes a specific structure of the TRFH

18 dimer created around the interface of the two monomers; hence, the residues selected were within helix

192 to helix 3 of the TRFH located in proximity to the dimer interface; (2) selected residues were

20 exposed on the surface of the protein; (3) selected residues were not conserved in TRF1, since TRF1

21 is unable to recruit ORC (Higa et al., 2017b). Fourteen residues (Y73, G74, V88, P90, K93, E94, 22 H95, T96, S98, R102, E111, E112, S119, and M122) met these criteria (Figure 1A), and six TRF2

23 mutants were generated by substituting the selected residues with alanine (Y73A/G74A, V88A/P90A, $24 \mathrm{~K} 93 \mathrm{~A} / \mathrm{E} 94 \mathrm{~A} / \mathrm{H} 95 \mathrm{~A} / \mathrm{T} 96 \mathrm{~A}, \mathrm{~S} 98 \mathrm{~A} / \mathrm{R} 102 \mathrm{~A}, \mathrm{E} 111 \mathrm{~A} / \mathrm{E} 112 \mathrm{~A}$, and S119A/M122A; referred to as YG, VP, 25 KEHT, SR, EE and SM respectively). 
The ability of the mutants to recruit ORC was examined using the lacO-LacI assay (Figure 1B).

2 The results clearly showed that TRF2 (45-244) EE-LacI was defective in recruiting ORC1 to the lacO

3 array. In addition, YG, VP, KEHT, and SM mutants showed partially decreased co-localization with

4 ORC1, suggesting that these residues are also involved in the interaction with ORC.

5 Immunoprecipitation assays demonstrated that all the prepared mutants of TRF2 (45-244)-LacI can

6 bind to HA-TRF2 with similar affinity to that of wild-type TRF2 (45-244)-LacI (Figure 1C), indicating

7 that these mutations do not affect dimerization. TRF2 functions as a hub protein that directly binds

8 to telomeres and recruits various factors required for telomere maintenance. For example, a

9 component of shelterin complex, RAP1, binds to telomeres concomitant with TRF2 (Li et al., 2000;

10 Sfeir et al., 2010). In addition, several factors such as Apollo, SLX4, and RTEL1 access telomeres

11 by binding to the TRF2 TRFH domain, thereby facilitating telomeric DNA replication (Higa et al.,

12 2017a; Martínez and Blasco, 2015). Therefore, we next examined whether our TRF2 mutants were

13 proficient in binding to these partners (Figure 1D-G). YG, VP, EE, and SM mutants recruited Flag-

14 Apollo to the lacO array to a similar extent as wild-type TRF2 (Figure 1D). These mutants could

15 also bind RAP1 (Figure 1E), SLX4 (Figure 1F), and RTEL1 (Figure 1G) in immunoprecipitation

16 assays. Collectively, these results suggest that TRF2 EE is a specific TRF2 mutant defective in ORC

17 recruitment alone. 
bioRxiv preprint doi: https://doi.org/10.1101/2021.02.08.430303; this version posted February 8, 2021. The copyright holder for this preprint (which was not certified by peer review) is the author/funder, who has granted bioRxiv a license to display the preprint in perpetuity. It is made available under aCC-BY 4.0 International license.

A

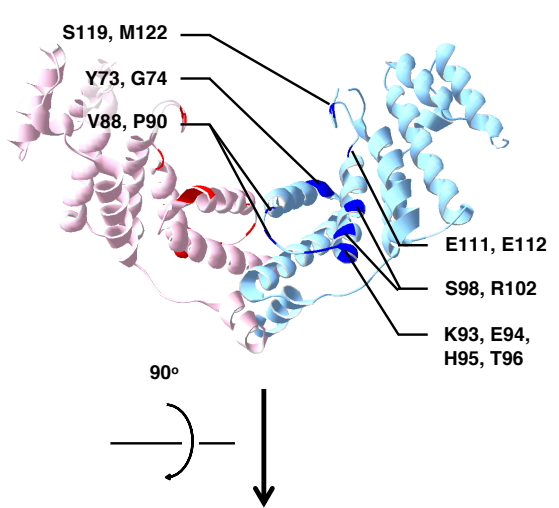

B

\begin{tabular}{ccccc}
\hline & $\begin{array}{c}\text { Lacl } \\
\text { foci a }\end{array}$ & $\begin{array}{c}\text { Co-loc. } \\
\text { foci }^{\mathrm{b}}\end{array}$ & $\begin{array}{c}\text { Co-loc. } \\
\text { freq. } \\
(\%)\end{array}$ & $\begin{array}{c}\boldsymbol{\chi}^{2-} \\
\text { test }^{\mathrm{d}}\end{array}$ \\
\hline HA-Lacl & 182 & 7 & 3.8 & $* * *$ \\
\hline TRF2 (45-244)-Lacl & 152 & 53 & 34.9 & \\
\hline TRF2 (45-244) YG-Lacl & 192 & 27 & 14.1 & $* * *$ \\
TRF2 (45-244) VP-Lacl & 158 & 19 & 12.0 & $* * *$ \\
TRF2 (45-244) KEHT-Lacl & 209 & 41 & 19.6 & $* *$ \\
TRF2 (45-244) SR-Lacl & 209 & 66 & 31.6 & n.s. \\
TRF2 (45-244) EE-Lacl & 202 & 12 & 5.9 & $* * *$ \\
TRF2 (45-244) SM-Lacl & 191 & 24 & 12.7 & $* * *$ \\
\hline
\end{tabular}

C

HA-TRF2

\begin{tabular}{|c|c|c|c|c|c|c|c|}
\hline \multirow{2}{*}{ 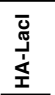 } & \multicolumn{7}{|c|}{ TRF2 (45-244)-Lacl } \\
\hline & YG & VP & KEHT & SR & EE & SM & WT \\
\hline
\end{tabular}

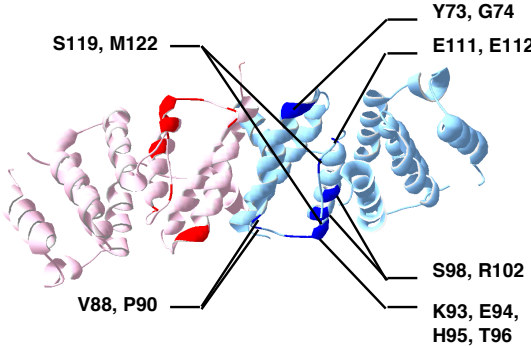

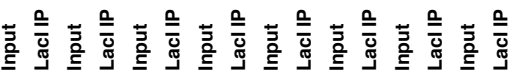

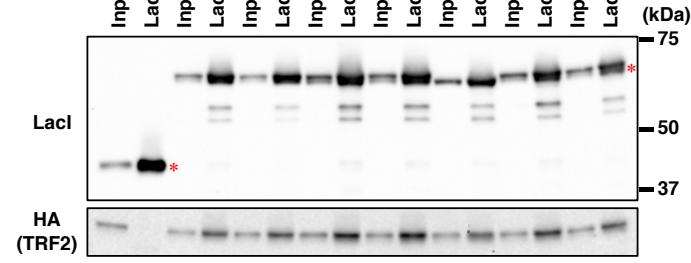

D

\begin{tabular}{|c|c|c|c|c|c|}
\hline Prey & Bait & $\begin{array}{l}\text { Lacl } \\
\text { foci } \text { a }^{2}\end{array}$ & $\begin{array}{l}\text { Co-loc. } \\
\text { foci }{ }^{\text {b }}\end{array}$ & $\begin{array}{c}\text { Co-loc. } \\
\text { freq. } \\
(\%)^{c} \\
\end{array}$ & $\begin{array}{c}x^{2-} \\
\text { test }^{\text {d }}\end{array}$ \\
\hline \multirow{6}{*}{$\begin{array}{l}\text { FLAG- } \\
\text { Apollo }\end{array}$} & HA-Lacl & 169 & 3 & 1.8 & \\
\hline & $\begin{array}{c}\text { TRF2 (45-244) } \\
\text {-Lacl }\end{array}$ & 149 & 116 & 77.9 & *** \\
\hline & $\begin{array}{c}\text { TRF2 (45-244) } \\
\text { YG-Lacl }\end{array}$ & 145 & 118 & 81.4 & *** \\
\hline & $\begin{array}{c}\text { TRF2 (45-244) } \\
\text { VP-Lacl }\end{array}$ & 145 & 116 & 80.0 & $* * *$ \\
\hline & $\begin{array}{c}\text { TRF2 (45-244) } \\
\text { EE-Lacl }\end{array}$ & 173 & 132 & 76.3 & *** \\
\hline & $\begin{array}{c}\text { TRF2 (45-244) } \\
\text { SM-Lacl }\end{array}$ & 154 & 127 & 82.5 & $* * *$ \\
\hline
\end{tabular}

$\mathbf{E}$

HA-TRF2

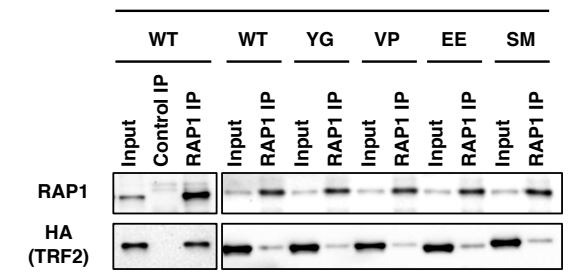

G

HA-TRF2
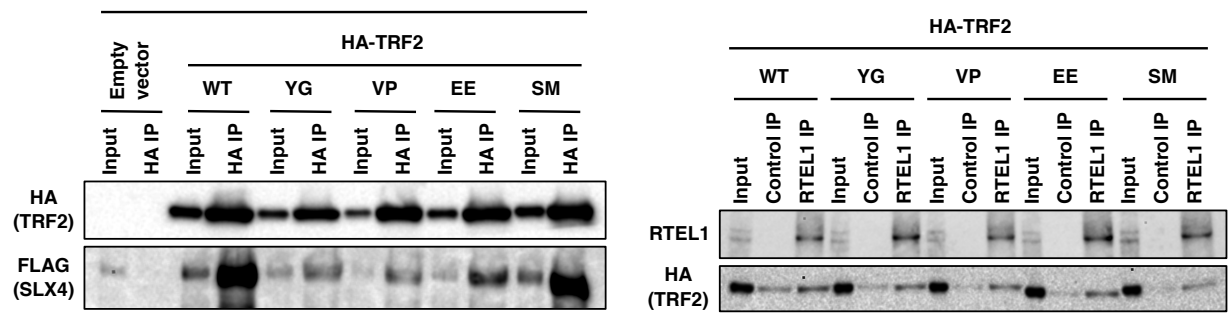

Figure 1. Generation and characterization of a series of TRF2 mutants with alanine-substitutions in the TRFH domain.

(A) Crystal structure of the TRF2 TRFH domain (PDB code 4M7C). Amino acid residues mutated in this study are highlighted and individual TRF2 monomers are depicted with cyan and pink ribbons. The 14 selected residues are marked with blue or red. Top, front view. Bottom, top view. (B) U2OS 2-6-3 cells were transfected with HALacl, TRF2 (45-255)-Lacl, or alanine-substitution mutant TRF2 (45-244)-Lacl (YG, VP, KEHT, SR, EE, and SM) for $24 \mathrm{~h}$, and then co-immunostained with anti-Lacl antibody and anti-ORC1 antibody, followed by DAPI counterstaining. Co-localization frequencies of ORC1 with Lacl proteins were examined. The values represent the sum scores from two biologically independent experiments. ${ }^{a}$ Total number of Lacl foci. b Number of Lacl foci co-localizing with ORC1 foci. ${ }^{\mathrm{c}} \mathrm{Co}-\mathrm{localization}$ frequency of ORC1 foci with Lacl foci. ${ }^{d}$ Results of the $\chi^{2}$ test vs. TRF2 (45-244)-Lacl. ${ }^{* *}, \mathrm{P}<0.01 ; * * *, \mathrm{P}<0.001 ; \mathrm{n}$.s., not significant. (C) U2OS cells were co-transfected with the indicated expression vectors. At $42 \mathrm{~h}$ post-transfection, cells were harvested and subjected to immunoprecipitation with anti-Lacl antibody. Immunoprecipitates (IPs) and $3 \%$ of the input were separated by SDS-PAGE, followed by immunoblotting with the indicated antibodies. Asterisks indicate the position of full-length Lacl-fused proteins. WT, wild-type. (D) U2OS 2-6-3 cells were co-transfected with the indicated expression vectors for $24 \mathrm{~h}$. Co-localization frequency of FLAG-Apollo and Lacl-fused proteins was examined. The values represent the sum scores from at least two biologically independent experiments. ${ }^{a}$ Total number of Lacl foci. ${ }^{b} \mathrm{Number}$ of Lacl foci colocalizing with FLAG-Apollo foci. ' Co-localization frequency of FLAG-Apollo foci with Lacl foci. d Results of the $\chi^{2}$ test vs. HA-Lacl. ${ }^{* * *}$, P < 0.001 . (E) At $42 \mathrm{~h}$ posttransfection with the indicated vectors, HCT116 cells were harvested and immunoprecipitated with an anti-RAP1 antibody or normal rabbit IgG (Control IP). IPs and $3 \%$ of input were analyzed by immunoblotting with the indicated antibodies. (F) At $42 \mathrm{~h}$ post-transfection with the indicated vectors, HEK293T cells were harvested and immunoprecipitated with an anti-HA antibody. IPs and $0.5 \%$ of input were analyzed by immunoblotting with the indicated antibodies. (G) HEK293T cells were cotransfected with the indicated expression vectors for $42 \mathrm{~h}$, cross-linked with formaldehyde and then solubilized. Soluble fractions were immunoprecipitated with an anti-RTEL1 antibody or normal mouse IgG (Control IP). IPs and $2 \%$ of input for RTEL1 or $0.1 \%$ of input for HA were analyzed by immunoblotting with the indicated antibodies. 
Recruitment of ORC and MCM to telomeres is inhibited by the TRF2 E111A/E112A mutation

in HeLa cells.

3 To evaluate the effects of substitution of endogenous wild-type TRF2 with the TRF2 EE mutant, we

4 established HeLa clones carrying EE mutations in the TERF2 gene by gene-editing using CRISPR-

5 Cas9 and single stranded oligonucleotide DNA (ssODN) encoding the EE mutations and a diagnostic

6 NruI restriction site (Figure 2A-D). Gene-editing with an ssODN that introduced the NruI site alone was performed in parallel to establish a control clone (Figure 2A, ssODN WT). Restriction fragment length polymorphism (RFLP) analysis showed that TRF2 WT 7-1, TRF2 EE 4-3, and TRF2 EE 7-7 clones have at least one TERF2 allele carrying the mutated sequences with the newly introduced NruI

10 site (Figure 2B). The target sites in the TERF2 gene exon 2 were amplified and sequenced, as 11 described in Materials and Methods, and no wild-type sequences or in-frame insertions/deletions were 12 detected (Figure 2C). In all TRF2-edited clones, TRF2 protein levels were decreased to $20-40 \%$ of 13 that in the parental HeLa cell line (Figure 2D). It is possible that this is caused by frameshift 14 mutations in other TRF2 alleles. To examine whether TRF2 EE affects the recruitment of ORC to 15 telomeres, ChIP-qPCR assays to examine telomere-specific chromatin loading were performed using 16 an anti-FLAG antibody in TRF2-edited clones expressing ORC1-3×FLAG (Figure 2E and Figure 2-

17 figure supplement 1), and telomere DNA enrichment relative to the LMNB2 replication origin (Giacca 18 et al., 1994; Sugimoto et al., 2011) was calculated (Figure 2E). ORC1 binding to telomeres was 19 decreased to approximately $60 \%$ in the WT clone compared with the parental HeLa cells. This 20 decrease may be associated with the reduced TRF2 protein levels in the WT clone. In the two EE 21 clones, ORC1 binding to telomeres was decreased 4-fold compared with the WT clone. This 22 impairment was not attributable to the expression level of ORC1-3 $\times$ FLAG (Figure 2F) or to cell cycle 23 distribution (Figure 2G). We next examined whether MCM recruitment to telomeres was affected in 24 the TRF2-edited clones using MCM7 ChIP-qPCR. MCM7 binding to telomeres was significantly 25 decreased in the two EE clones when compared with the WT clone (Figure 2H), while MCM7 DNA 
1 binding in general was unaffected (Figure 2I). These data suggest that TRF2-ORC binding is critical 2 for the recruitment of ORC and MCM to telomeres. 
bioRxiv preprint doi: https://doi.org/10.1101/2021.02.08.430303; this version posted February 8, 2021. The copyright holder for this preprint (which was not certified by peer review) is the author/funder, who has granted bioRxiv a license to display the preprint in perpetuity. It is made available under aCC-BY 4.0 International license.

A

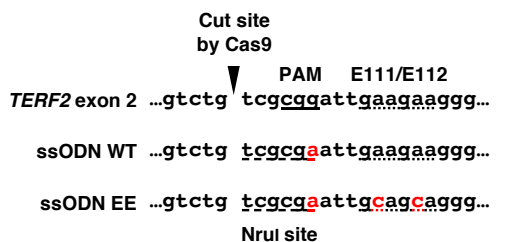

C

\begin{tabular}{lll}
\hline clone & alleles & \\
\hline TRF2 WT 7-1 & $\begin{array}{l}\text { WT target sequence } \\
(3 / 11)\end{array}$ & $\begin{array}{l}\text { the } 50 \text { bp deletion } \\
(8 / 11)\end{array}$ \\
& EE target sequence & $\begin{array}{l}\text { the } 1 \text { bp insertion } \\
(6 / 11)\end{array}$ \\
TRF2 EE 4-3 & $(5 / 11)$ & \\
& EE target sequence \\
TRF2 EE 7-7 & $(11 / 11)$ & \\
\hline
\end{tabular}

B

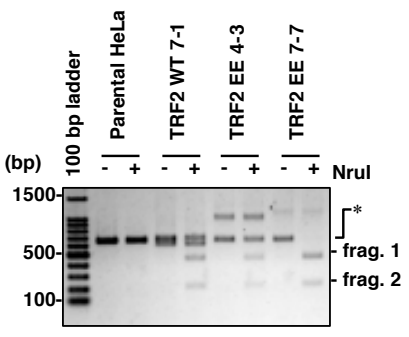

D
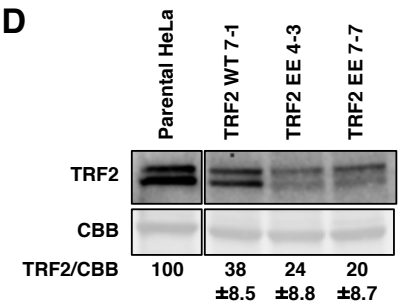

E

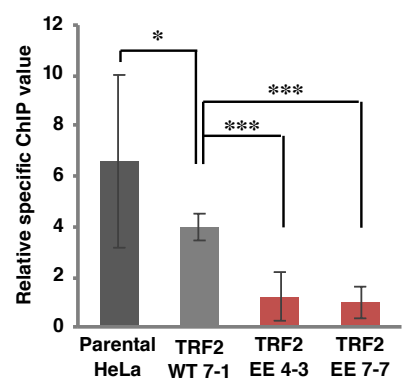

H

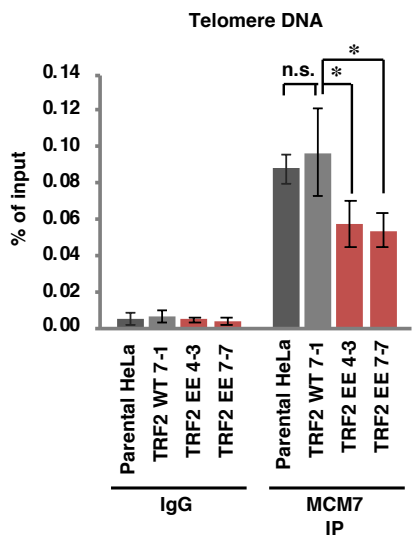

$\mathbf{F}$

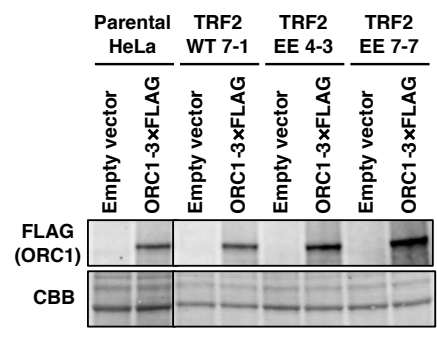

I

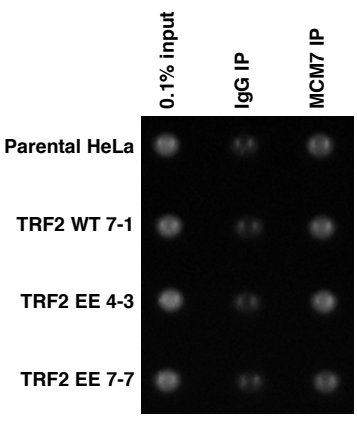

G

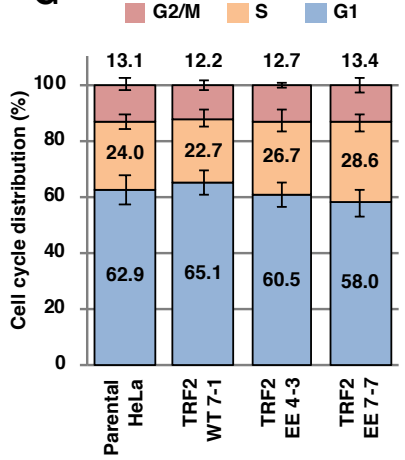

Total DNA

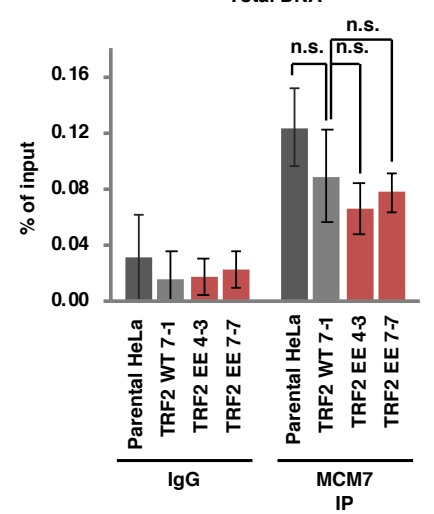

Figure 2. ORC recruitment to telomeres is impaired in TRF2 EE clones.

(A) The sequences of single stranded oligo DNA (SSODN) used to establish TRF2-edited HeLa clones. Top, reference sequence of the target site. Middle, ssODN used for the TRF2 WT clone. Bottom, ssODN used for TRF2 EE clones. Introduced mutations are shown in red. The PAM sequence required for Cas 9 recognition is underlined. Codons corresponding to the E111/E112 residues are marked with a dotted underline. The newly introduced Nrul site is marked with a dashed underline. (B) Restriction fragment length polymorphism analysis of the HeLa clones. The target site was amplified from genomic DNA derived from each cell line by PCR. Amplicons were incubated with or without Nrul restriction enzyme and then separated by agarose gel electrophoresis, followed by EtBr staining. When the target genes were edited, Nrul treatment produced 427 bp and 209 bp fragments (frag. 1 and frag. 2, respectively) from the 636 bp PCR product (*). (C) Summary of the sequencing of the target sites in the TERF2 gene of each cell line. For detail, see Materials and Methods. Eleven colonies from each clone were analyzed. (D) Whole cell extracts were separated by SDS-PAGE, and then analyzed by immunoblotting with anti-TRF2 antibody or by CBB staining (as a loading control). The signal intensities of TRF2 and CBB bands were quantified, and the TRF2/CBB signal ratio is shown relative to that of parental HeLa cells. The means \pm SDs are shown ( $n=3$ ). (E-F) At $48 \mathrm{~h}$ post-transfection with empty vector or ORC1-3 $\times$ FLAG expression vector, cells were subjected to ChIP with an anti-FLAG antibody. (E) Purified DNA from input and immunoprecipitates was analyzed by qPCR with primer pairs amplifying either a telomeric sequence or the $L M N B 2$ replication origin. Relative specific ChIP values were calculated as follows: (Telomeric DNA as a \% of input from ORC1-3 $\times$ FLAG ChIP - Telomeric DNA as a \% of input from empty vector ChIP) / (LMNB2 origin DNA as a \% of input from ORC1-3 $\times$ Flag ChIP $-\angle M N B 2$ origin DNA as a $\%$ of input from empty vector ChIP). The means \pm SDs are shown $(n=9)$. ${ }^{*} P<0.05$ $* * *, P<0.001$ (two-tailed Student's $t$-test). (F) Lysates were separated by SDS-PAGE and then analyzed by immunoblotting with anti-FLAG antibody and by CBB staining (as a loading control). (G) Cells were harvested and stained with propidium iodide to allow cell cycle analysis by flow cytometry. The means \pm SDs are shown $(n=3)$. ( $H$ and I) Cells were subjected to ChIP assay with control IgG or anti-MCM7 antibody. (H) Purified DNAs from input and immunoprecipitates were analyzed by qPCR with a primer pair amplifying a telomeric sequence. Results are shown as the percent of input DNA. The means \pm SDs are shown $(n=4)$. ${ }^{*}, \mathrm{P}<$ $0.05 ;$ n.s., not significant (two-tailed Student's t-test). (I) Left, the total amounts of co-precipitated DNA and input DNA were analyzed using SYBR Gold staining and UV photography. Right, results are shown as the percent of input DNA. The means \pm SDs are shown $(n=4)$. n.s., not significant (two-tailed Student's $t$-test). 


\section{ORC1-3xFlag ChIP - qPCR}

Telomere qPCR

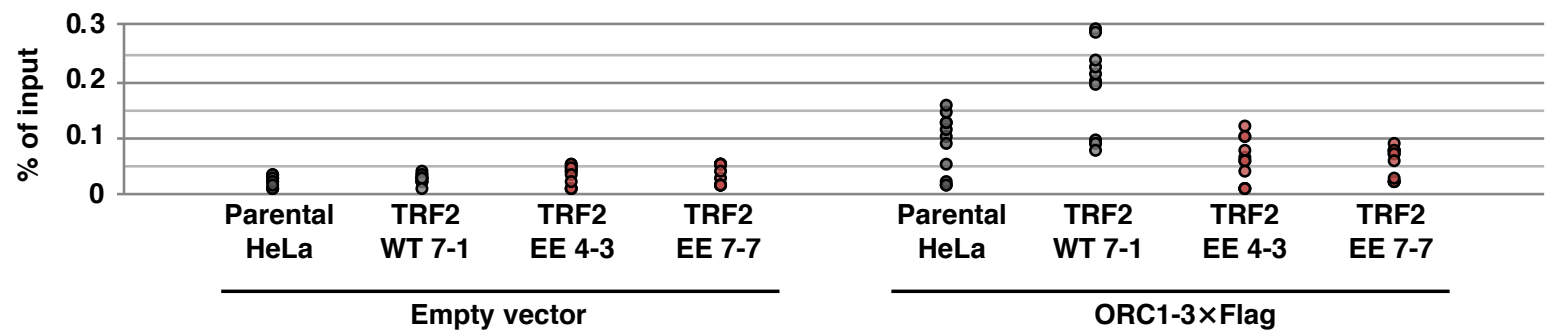

LMNB2 origin qPCR

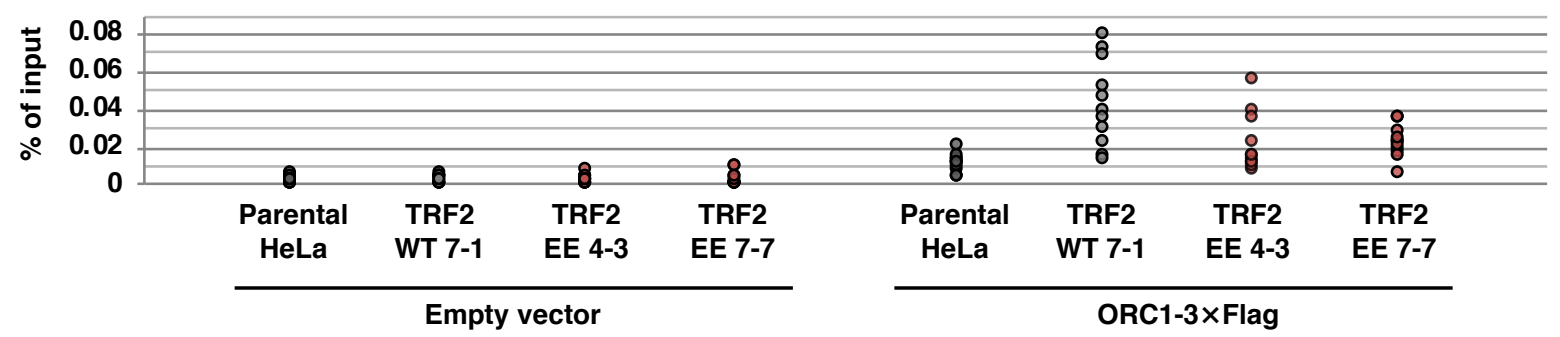

Figure 2-figure supplement 1. Source data of ChIP experiments.

$\%$ of input values used for the calculation in Figure $2 \mathrm{E}$ are shown. 
Telomere maintenance is impaired in HeLa TRF2 E111A/E112A clones under DNA replication

\section{stress conditions.}

3 The phenotype of TRF2-edited clones was analyzed with particular focus on telomere maintenance

4 under DNA replication stress conditions. First, we investigated telomere DNA damage. After

5 exposing cells to $0.1 \mathrm{mM}$ hydroxyurea (HU), telomeres and 53BP1, a marker for DNA double-strand

6 breaks (Panier and Boulton, 2014), were visualized by fluorescence in situ hybridization (FISH) with

7 a peptide nucleic acid (PNA) probe targeting a telomere-specific sequence, and immunofluorescence

8 staining, respectively (Figure 3A and B). In the absence of HU-induced replication stress, the number

9 of telomere dysfunction-induced foci (TIFs), detected as telomeric foci co-localizing with 53BP1

10 (d'Adda di Fagagna et al., 2003; Takai et al., 2003), increased in the WT clone (Figure 3B, Parental

$11 \mathrm{HeLa} / \mathrm{DDW}$ vs. WT 7-1/DDW). This increase is possibly related to the decreased TRF2 protein level

12 in WT 7-1 (see Figure 2D), which may lead to insufficient telomere protection (Celli and de Lange,

13 2005; van Steensel et al., 1998). In the absence of HU, the number of endogenous TIFs in the two

14 EE clones were comparable to the WT clone, suggesting that there was no increase in the basal level

15 of telomere damage in the EE clones. Importantly, HU treatment increased the number of TIFs in

16 the two EE clones but not in the WT clone, indicating a defect in the response to HU-induced telomere

17 replication stress in the EE clones.

Defective DNA replication leads to micronuclei formation (Chan et al., 2009; Ying et al., 2013);

19 therefore, we next measured the number of micronuclei containing telomeric FISH signals (telomere-

20 containing micronuclei) as an index of telomere instability (Lindberg et al., 2008) (Figure 3C and D).

21 In the absence of HU, the frequency of telomere-containing micronuclei did not differ between the cell

22 lines tested. However, HU induced significantly more telomere-containing micronuclei in EE clones

23 than the WT clone (approximately 2-fold). Taken together, these results suggest that TRF2-mediated

24 recruitment of ORC to telomeres contributes to the maintenance of telomere stability under DNA

25 replication stress conditions. 
A
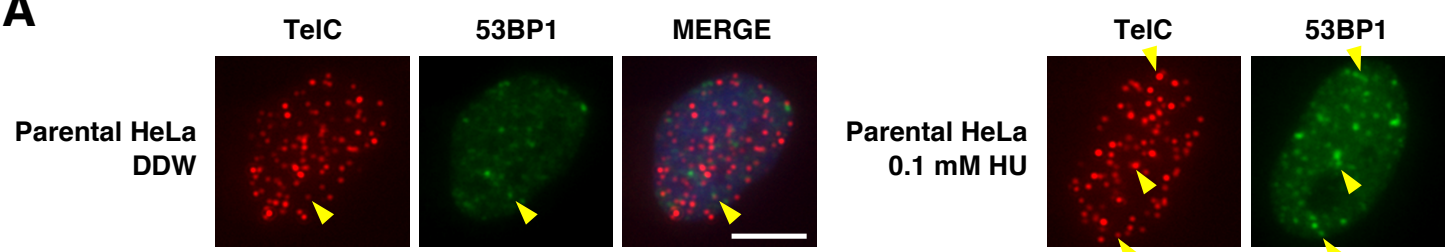

MERGE

TRF2 EE 4-3
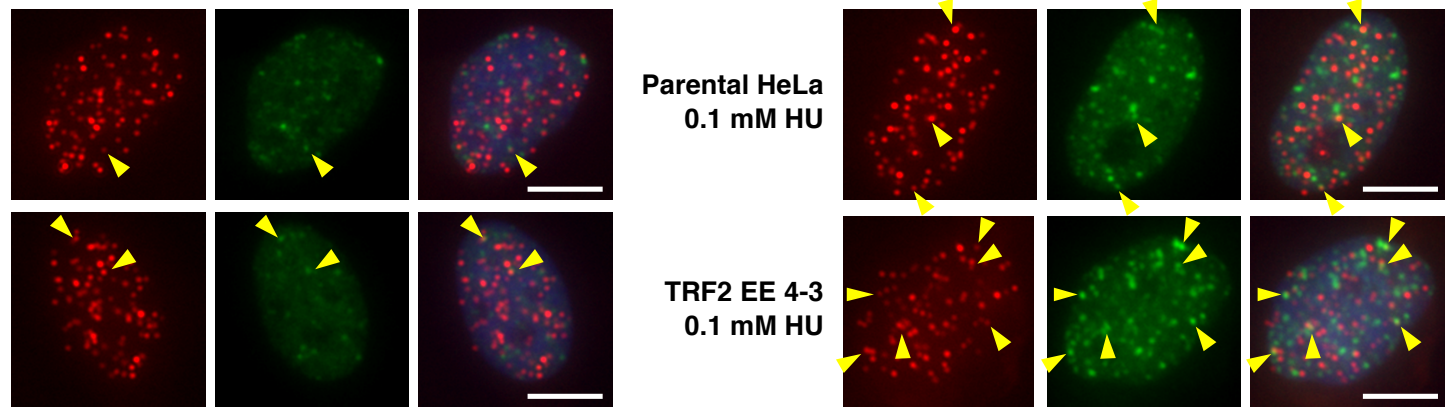

B

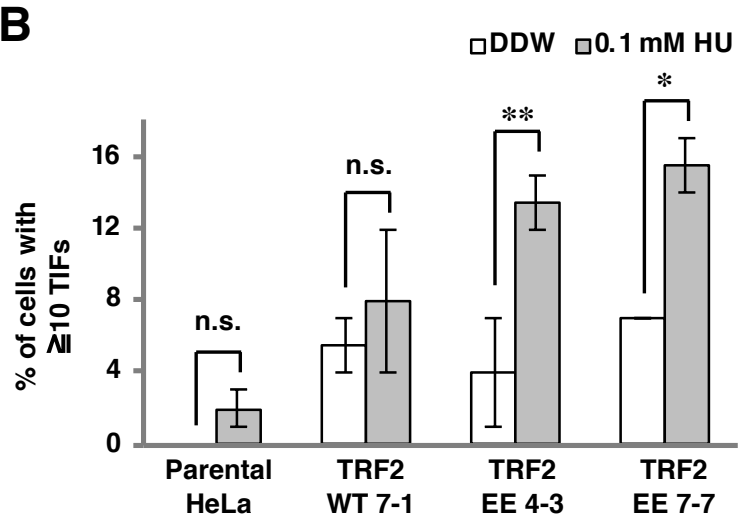

C

\section{Parental HeLa \\ $0.1 \mathrm{mM} \mathrm{HU}$}

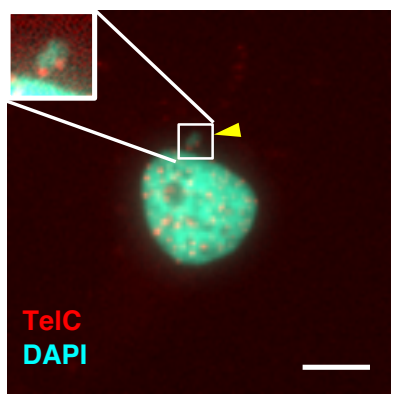

TRF2 EE 4-3

$0.1 \mathrm{mM} \mathrm{HU}$

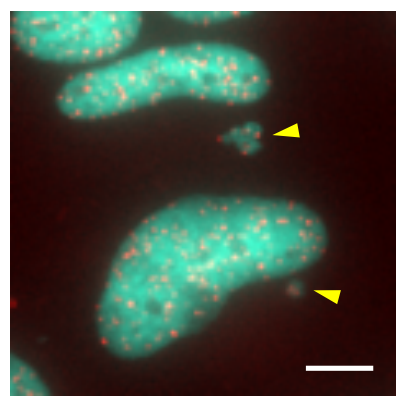

D

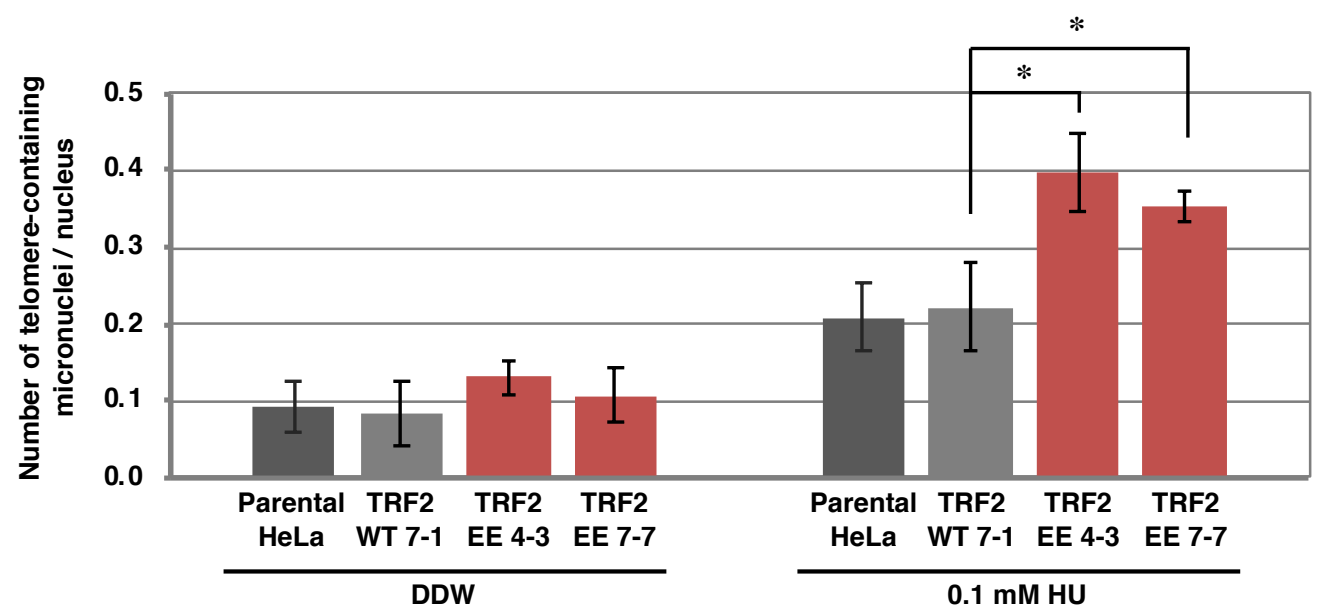

Figure 3. Telomere instability in TRF2 EE clones upon DNA replication stress.

(A and B) Cells treated with $0.1 \mathrm{mM}$ hydroxyurea (HU) for $16 \mathrm{~h}$ were stained with PNA FISH using a telomere probe (TelC, red), followed by immunostaining with anti-53BP1 antibody (green) and DAPI counterstaining (blue). (A) Representative images; telomere foci co-localizing with 53BP1 (53BP1 TIFs) are indicated by yellow arrowheads. Scale bar, $10 \mathrm{~mm}$. (B) The frequencies of cells carrying $\geq 10$ 53BP1 TIFs were quantified. The means \pm SDs are shown $(n=2)$. One hundred cells were analyzed for each sample. The sum scores are used for statistical analyses. n.s., not significant; ${ }^{*}, \mathrm{P}<0.05 ;{ }^{* *}, \mathrm{P}<0.01$ (Fisher's exact test). (C and D) Cells treated with $0.1 \mathrm{mM} \mathrm{HU}$ for $72 \mathrm{~h}$ were stained with PNA-FISH using a telomere probe (red), followed by DAPI counterstaining (cyan). (C) Representative images; telomere-containing micronuclei are indicated by yellow arrowheads. Scale bar, $10 \mathrm{~mm}$. (D) The number of nuclei and telomere-containing micronuclei were counted, and the ratio of telomere-containing micronuclei/nucleus was calculated. The means \pm SDs are shown $(n=3)$. At least 82 cells were analyzed for each sample. ${ }^{*}, P<$ 0.05 (two-tailed Student's $t$-test). 
A broad region of ORC1 including amino acids $411-510$ is required for the recruitment by TRF2.

As an alternative approach to evaluate the physiological significance of the TRF2-ORC interaction, we searched for a specific ORC1 mutant specifically defective for TRF2 binding alone. Several proteins that bind to the TRFH domain of TRF2, such as Apollo and SLX4, share a TRF2 binding motif (F/Y/HxLxP) (Chen et al., 2008; Wan et al., 2013). The leucine residues in the binding motifs of Apollo and SLX4 are important for their interaction with TRF2 (Chen et al., 2008; Wan et al., 2013). This short motif is similarly found in human ORC1 at amino acid 227-231 (HTLTP). However, an ORC1 L229A mutant could be recruited by TRF2 in the lacO-LacI assay (Figure 4-figure supplement 1), suggesting that, unlike Apollo and SLX4, this motif in ORC1 may not be involved in TRF2 binding. Next, we generated a series of ORC1 truncation mutants (Figure 4A) and examined their recruitment by TRF2 (45-244)-LacI (Figure 4B). Transiently-expressed FLAG-ORC1 (2-511) frequently co-localized with TRF2 (45-244)-LacI (73\%), indicating that the C-terminal AAA+

13 (ATPases associated with diverse cellular activities) and WH (winged-helix) domains are dispensable

14 for binding to TRF2. By contrast, three further ORC1 truncation mutants $(2-325,2-244$, and 2-85)

15 were not recruited by TRF2 (45-244)-LacI, suggesting that a region spanning amino acid 326-511 of 16 ORC1 is required for TRF2 binding. In addition, ORC1 (244-511), but not ORC1 (325-511), co-

17 localized more frequently with TRF2 (45-244)-LacI ( $\sim 90 \%$ and $\sim 46 \%$, respectively) than ORC1 (2-

18 511) (73\%). These data suggest that ORC1 efficiently binds to TRF2 via a relatively broad region 19 that includes amino acids 244-511. This is consistent with a previous report that GST-ORC1 (20120 511) interacts with TRF2 in HeLa cell extracts (Atanasiu et al., 2006).

To further narrow the region required for TRF2 binding, we analyzed the recruitment of fulllength ORC1 mutants lacking amino acids within the 326-510 region (Figure 4C and D). TRF2 (45-

23 244)-LacI recruited N-terminal FLAG-tagged ORC1 (full-length) at a significantly higher frequency $24(26 \%)$ than the control HA-LacI $(9 \%)$. However, ORC1 $(\Delta 326-510)$, ORC1 $(\Delta 386-510)$, and ORC1 25 ( $\triangle 411-510)$ co-localized with TRF2 (45-244)-LacI at low frequencies, indicating that amino acids 
$1411-510$ of ORC1 are necessary for the recruitment by TRF2. By contrast, ORC1 $(\Delta 446-510)$ and

2 ORC1 $(\Delta 411-445)$ partially retained its ability to bind to TRF2. These results suggest that multiple

3 residues distributed across the 411-510 region are responsible for binding to TRF2. Because the loss

4 of such a broad region is likely to have adverse effects on ORC1 stability and function, we considered

5 ORC1 $(\Delta 411-510)$ to be an unsuitable candidate for a specific ORC1 mutant defective only in TRF2

6 binding. 
bioRxiv preprint doi: https://doi.org/10.1101/2021.02.08.430303; this version posted February 8, 2021. The copyright holder for this preprint (which was not certified by peer review) is the author/funder, who has granted bioRxiv a license to display the preprint in perpetuity. It is made available under aCC-BY 4.0 International license.

A

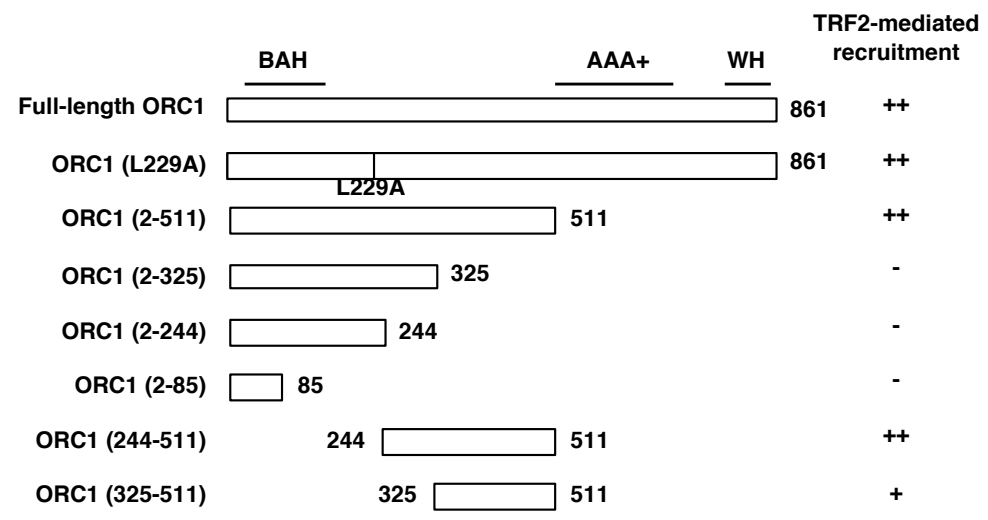

B

\begin{tabular}{cccccc}
\hline \multirow{2}{*}{ Bait } & Prey & $\begin{array}{c}\text { Lacl } \\
\text { foci }\end{array}$ & $\begin{array}{c}\text { Co-loc. } \\
\text { foci }\end{array}$ & $\begin{array}{c}\text { Co-loc. } \\
\text { freq. (\%) }\end{array}$ & $\boldsymbol{x}^{2 \text {-test d }}$ \\
\hline \multirow{2}{*}{ HA-Lacl } & FLAG-ORC1 (2-511) & 157 & 12 & 7.6 & \\
\hline & FLAG-ORC1 (2-511) & 112 & 82 & 73.2 & $* * *$ \\
\cline { 2 - 6 } & FLAG-ORC1 (2-325) & 113 & 7 & 6.2 & n.s. \\
\cline { 2 - 6 } TRF2 (45-244)-Lacl & FLAG-ORC1 (2-244) & 119 & 6 & 5.0 & n.s. \\
\cline { 2 - 6 } & FLAG-ORC1 (2-85) & 153 & 2 & 1.3 & n.s. \\
\cline { 2 - 6 } & FLAG-ORC1 (244-511) & 124 & 112 & 90.3 & $* * *$ \\
\cline { 2 - 6 } & FLAG-ORC1 (325-511) & 161 & 75 & 46.6 & $* * *$ \\
\hline
\end{tabular}

C

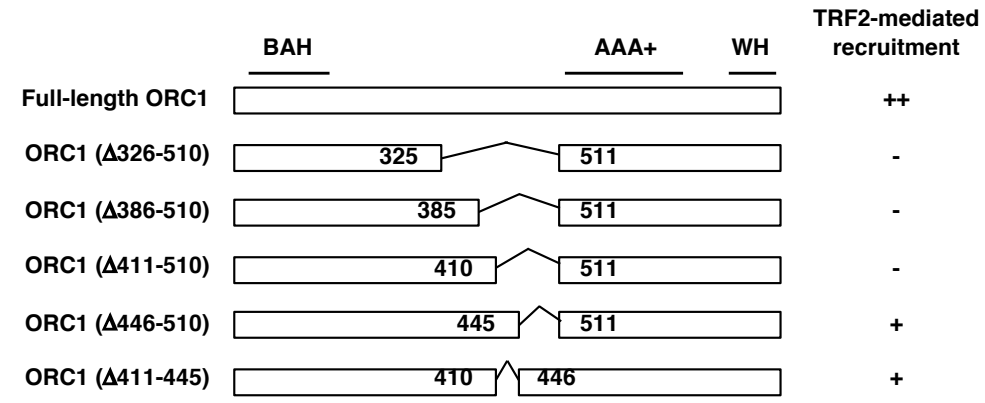

D

\begin{tabular}{cccccc}
\hline Bait & Prey & $\begin{array}{c}\text { Lacl } \\
\text { foci }\end{array}$ & $\begin{array}{c}\text { Co-loc. } \\
\text { foci }\end{array}$ & $\begin{array}{c}\text { Co-loc. } \\
\text { freq. }(\%)\end{array}$ & $\chi^{2}$-test ${ }^{\text {e }}$ \\
\hline HA-Lacl & FLAG-ORC1 (full-length) & 318 & 30 & 9.4 & \\
\hline & FLAG-ORC1 (full-length) & 290 & 76 & 26 & $* * *$ \\
\cline { 2 - 6 } & FLAG-ORC1 $(\Delta 326-510)$ & 255 & 20 & 7.8 & n.s. \\
\cline { 2 - 6 } TRF2 (45-244)-Lacl & FLAG-ORC1 $(\Delta 386-510)$ & 220 & 25 & 11 & n.s. \\
\cline { 2 - 6 } & FLAG-ORC1 $(\Delta 411-510)$ & 296 & 19 & 6.4 & n.s. \\
\cline { 2 - 6 } & FLAG-ORC1 $(\Delta 446-510)$ & 303 & 56 & 18 & $* *$ \\
\cline { 2 - 6 } & FLAG-ORC1 $(\Delta 411-445)$ & 238 & 37 & 16 & $*$ \\
\hline
\end{tabular}

Figure 4. ORC1 amino acids 411-510 are required for efficient ORC1 recruitment by TRF2.

(A and C) Schematics of ORC1 mutants used in this study. Domain information is shown at the top. A summary of their ability to bind TRF2 is shown on the right (see Figure 4B, D and Expanded View Figure EV2 for detail). BAH, bromo adjacent homology domain; AAA+, ATPase associated with diverse cellular activities domain; WH, winged helix domain. (B and D) Summary of the co-localization frequencies of ORC1 mutants with TRF2 (45-244)-Lacl. U2OS 2-6-3 cells were co-transfected with the indicated ORC1 and Lacl expression vectors. Co-localization frequency was examined as in Figure 1B. The values represent the sum score from at least two biologically independent experiments. ${ }^{a}$ Total number of Lacl foci. ${ }^{b}$ Number of Lacl foci co-localizing with FLAG foci. ${ }^{\mathrm{c}}$ Co-localization frequency of FLAG foci with Lacl foci. ${ }^{d}$ Results of the $\chi^{2}$ test vs. co-localization of HA-Lacl and FLAG-ORC1 (2-511). e Results of the $\chi^{2}$ test vs. co-localization of HA-Lacl and FLAG-ORC1 (full-length). ${ }^{*}, \mathrm{P}<0.05 ;{ }^{* *}, \mathrm{P}<0.01 ;{ }^{* * *}, \mathrm{P}<0.001$; n.s., not significant. 
bioRxiv preprint doi: https://doi.org/10.1101/2021.02.08.430303; this version posted February 8,2021 . The copyright holder for this preprint (which was not certified by peer review) is the author/funder, who has granted bioRxiv a license to display the preprint in perpetuity. It is made available under aCC-BY 4.0 International license.

\begin{tabular}{cccccc}
\hline \multirow{2}{*}{ Prey } & Bait & $\begin{array}{c}\text { Lacl } \\
\text { foci a }\end{array}$ & $\begin{array}{c}\text { Co-loc. } \\
\text { foci } \text { b }\end{array}$ & $\begin{array}{c}\text { Co-loc. } \\
\text { freq. (\%) }\end{array}$ & $\begin{array}{c}\boldsymbol{x}^{2-} \\
\text { test d }\end{array}$ \\
\hline \multirow{2}{*}{ ORC1-3xFLAG } & HA-Lacl & 125 & 1 & 0.8 & \\
\cline { 2 - 6 } & TRF2 $\Delta$ Myb-Lacl & 98 & 54 & 55.1 & $* * *$ \\
\hline \multirow{2}{*}{ ORC1 (L229A)-3xFLAG } & HA-Lacl & 71 & 5 & 7.0 & $* * *$ \\
\cline { 2 - 6 } & TRF2 $\triangle$ Myb-Lacl & 82 & 44 & 53.7 & $*$ \\
\hline
\end{tabular}

Figure 4-figure supplement 1. Co-localization frequencies of wild-type and L229A ORC1 with TRF2AMyb-Lacl. After co-transfection with the indicated ORC1 and Lacl expression vectors, U2OS 2-6-3 cells were subjected to co-immunostaining with anti-Lacl and anti-FLAG antibodies. Co-localization frequency was examined. The values represent the score from a single experiment. ${ }^{a}$ Total number of Lacl foci. ${ }^{b}$ Number of Lacl foci colocalizing with FLAG foci. ${ }^{c}$ Co-localization frequency of FLAG foci with Lacl foci. ${ }^{d}$ Results of the $\chi^{2}$ test in comparison with HA-Lacl. ${ }^{* * *}, \mathrm{P}<0.001$.

TRF2 $\triangle \mathrm{Myb}$, consisting of the amino acids 1-445 but lacking the Myb domain, has been reported to recruit ORC1 to the lacO array when fused to Lacl (Higa et al. 2017 BBA Mol Cell Res 1864: 191-201). The data presented show that the co-localization frequency of ORC1 (L229A)-3 × FLAG with TRF2DMyb-Lacl was 54\%, which was comparable to that of wild-type ORC1-3 $\times$ FLAG ( 55\%). 
1 Overexpression of an ORC1 (244-511) fragment competitively inhibits TRF2-ORC binding but does not affect the general function of ORC in the initiation of DNA replication.

3 Since the TRF2 binding sites reside within amino acids 244 and 511 of ORC1, we examined whether

4 overexpression of an ORC1 (244-511) construct could competitively inhibit the TRF2-ORC

5 interaction (Figure 5). As shown in Figure 5A, FLAG-ORC1 (244-511) bound to TRF2 and

6 competitively inhibited co-immunoprecipitation of full-length ORC1 with TRF2. In addition, overexpression of HA-ORC1 (244-511) impaired the TRF2 (45-244)-LacI-mediated recruitment of

8 ORC1 to the $l a c O$ array (Figure 5B). Next, we examined whether ORC1 (244-511) overexpression

9 affects the general ORC function during global DNA replication. Although MCM loading is tightly

10 regulated to prevent DNA re-replication, simultaneous deregulation of licensing factors (Cdt1+ORC1

11 or Cdt1+CDC6) can induce re-replication in HEK293T cells, which is detected by FACS as DNA

12 content higher than 4N (Sugimoto et al., 2009). We used this assay to examine the genome-wide

13 functions of ORC in the presence of FLAG-ORC1 (244-511) (Figure 5C-E). Consistent with a 14 previous report (Sugimoto et al., 2009), co-expression of $\mathrm{Cdt1}+\mathrm{ORC} 1$ induced significant re15 replication ( two-fold higher than that induced by expression of $\mathrm{Cdt} 1$ alone) (Figure 5C-E). This re16 replication was dependent on ORC1 ATPase activity, as a mutation in the Walker B motif (D620A) 17 abolished the induction of re-replication (Figure 5-figure supplement 1). Importantly, re-replication

18 was induced by Cdt1 + ORC1 to a similar extent in the presence and absence of FLAG-ORC1 (24419 511) (Figure 5C-E). These results suggest that overexpression of ORC1 (244-511) may specifically 20 inhibit TRF2-ORC interaction with little effect on the genome-wide replication activity of ORC. 
bioRxiv preprint doi: https://doi.org/10.1101/2021.02.08.430303; this version posted February 8, 2021. The copyright holder for this preprint (which was not certified by peer review) is the author/funder, who has granted bioRxiv a license to display the preprint in perpetuity. It is made available under aCC-BY 4.0 International license.

A
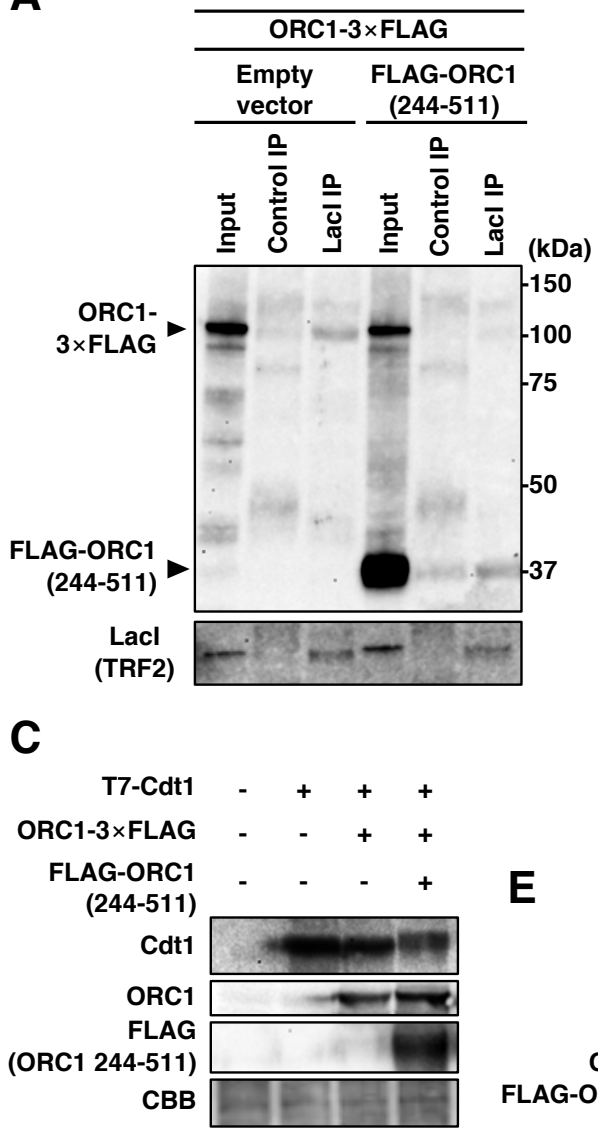

$\mathbf{E}$
B

\begin{tabular}{cccccc}
\hline & $\begin{array}{c}\text { HA- } \\
\text { ORC1 } \\
(244-511)\end{array}$ & $\begin{array}{c}\text { Lacl } \\
\text { foci a }\end{array}$ & $\begin{array}{c}\text { Co-loc. } \\
\text { foci } \mathrm{b}\end{array}$ & $\begin{array}{c}\text { Co-loc. } \\
\text { freq. } \\
(\%)^{\mathrm{c}}\end{array}$ & $\begin{array}{c}\boldsymbol{\chi}^{2-} \\
\text { test }\end{array}$ \\
\hline $\begin{array}{c}\text { TRF2 } \\
(45-244)-L a c l \\
+ \text { FLAG-ORC1 }\end{array}$ & - & 206 & 68 & 33 & \\
\cline { 2 - 6 } & + & 210 & 32 & 15 & $* * *$ \\
\hline
\end{tabular}

D

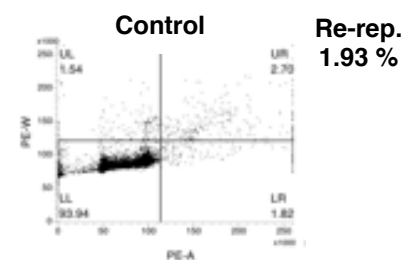

Cdt1 + ORC1

Re-rep.
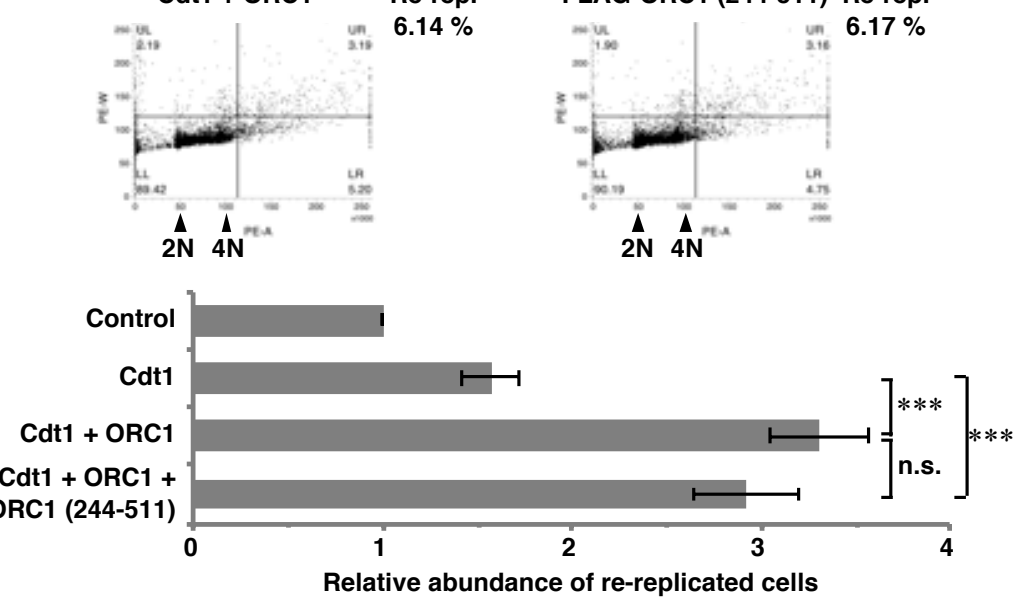

Figure 5. Overexpression of ORC1 (244-511) fragment competitively inhibits TRF2-ORC1 binding, but has little effect on the genomewide replication activity of ORC1.

(A) HEK293T cells were co-transfected with the indicated expression vectors (equal amounts of each plasmid) for $42 \mathrm{~h}$. After cross-linking with formaldehyde and solubilization, cell lysates were immunoprecipitated with anti-Lacl antibody or normal mouse IgG (Control). IPs and $1 \%$ of the input were immunoblotted with the anti-FLAG or anti-Lacl antibody. The data are representatives of two independent experiments. (B) U2OS 2-6-3 cells were co-transfected with the indicated expression vectors (equal amounts of each plasmid) for $24 \mathrm{~h}$, then double-immunostained with the indicated antibodies, followed by DAPI staining. Co-localization frequencies of FLAG-ORC1 foci with Lacl foci were examined. The values represent the sum score of two biologically independent experiments. ${ }^{a}$ Total number of Lacl foci. ${ }^{b}$ Number of Lacl foci co-localizing with FLAG-ORC1 foci. ${ }^{c}$ Co-localization frequency of FLAG-ORC1 foci with Lacl foci. ${ }^{d}$ Results of the $\chi^{2}$ test vs. co-localization of FLAG-ORC1 and TRF2 (45-244)-Lacl in the absence of HA-ORC1 (244-511). ${ }^{* * *}, \mathrm{P}<0.001$. (C-E) HEK293T cells were co-transfected with mixture of the expression vectors (equal amounts of each plasmid) or their empty vectors (-) as indicated for $48 \mathrm{~h}$. (C) Whole-cell lysates were subjected to immunoblotting with the indicated antibodies. CBB serves as a loading control. (D) DNA content was analyzed by flow cytometry. After excluding the sub-G1 fraction, the percentages of re-replicated cells (DNA content greater than $4 \mathrm{~N}$ ) were calculated (shown on the right). (E) The relative abundance of re-replicated cells as a proportion of control cells. The means and SDs from three biologically independent experiments were shown. ${ }^{* * *}, \mathrm{P}<0.001 ; \mathrm{n}$. s., not significant (Tukey-Kramer test). 
bioRxiv preprint doi: https://doi.org/10.1101/2021.02.08.430303; this version posted February 8, 2021. The copyright holder for this preprint (which was not certified by peer review) is the author/funder, who has granted bioRxiv a license to display the preprint in perpetuity. It is made available under aCC-BY 4.0 International license.

Experiment 1

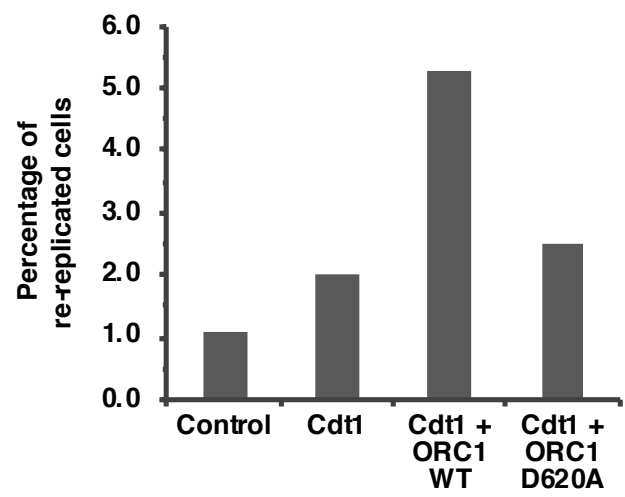

T7-Cdt1

ORC1 (WT)-3xFLAG

ORC1 (D620A)-3xFLAG

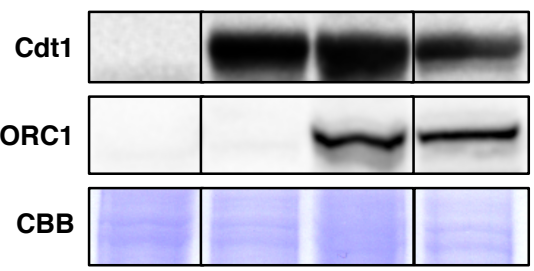

Experiment 2

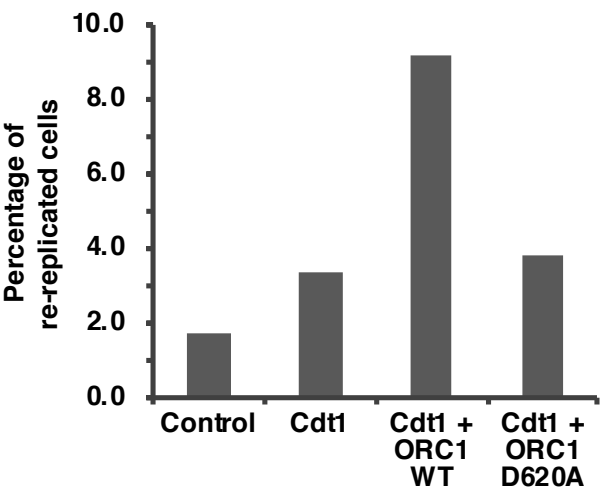

T7-Cdt1

ORC1 (WT)-3XFLAG

ORC1 (D620A)-3XFLAG

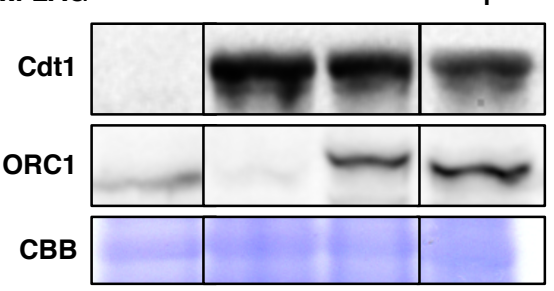

Figure 5-figure supplement 1. Re-replication induced by co-expression of Cdt1 + ORC1 is dependent on the ORC1 Walker B motif. HEK293T cells were co-transfected with a mixture of the expression vectors (T7-Cdt, ORC1 (WT)-3 × FLAG, and ORC1 (D620A)$3 \times$ FLAG) or their empty vectors (-), as indicated for $48 \mathrm{~h}$. Top, DNA content was analyzed by flow cytometry. The percentage of re-replicated cells was calculated as in Figure 5D. Bottom, whole-cell lysates were subjected to immunoblotting with the indicated antibodies. CBB staining serves as the loading control. The results of two independent experiments are shown. These data show that the disruption of ORC1 Walker B motif (D620A) abolishes re-replication induced by co-expression of Cdt1 + ORC1. 
1 Overexpression of ORC1 (244-511) compromises ORC and MCM recruitment to telomeres and

2 allows telomeric DNA damage to accumulate under replication stress conditions.

3 To investigate whether the overexpression of ORC1 (244-511) inhibits ORC binding to telomeres,

4 HeLa cells stably overexpressing HA-ORC1 (244-511) were established by retroviral infection

5 (Figure 6-figure supplement 1 A). Overexpression of HA-ORC1 (244-511) did not affect cell

6 proliferation or cell cycle distribution (Figure 6-figure supplement 1 B and C). When ORC1-

$73 \times$ FLAG was transiently expressed in these cells to perform anti-FLAG ChIP analysis (Figure 6A),

8 ORC1-3×FLAG binding at telomeres was significantly reduced upon overexpression of HA-ORC1

9 (244-511) (Figure 6B and Figure 6-figure supplement 2). Furthermore, overexpression of HA-

10 ORC1 (244-511) significantly decreased MCM loading at telomeres (Figure 6C), while the total DNA

11 co-precipitated with an anti-MCM7 antibody was unchanged (Figure 6D). These results suggest that

12 HA-ORC1 (244-511) specifically impairs telomere binding of ORC and MCM. Using telomere-

13 FISH and immunostaining of 53BP1, we next examined telomeric DNA damage upon overexpression

14 of HA-ORC1 (244-511) (Figure 6E). In the absence of exogenous replication stress (Figure 6E;

15 DDW), levels of spontaneous TIF-positive cells were low in both the control and HA-ORC1 (244-

16 511)-overexpressing cells. When treated with $0.1 \mathrm{mM} \mathrm{HU}$, cells overexpressing HA-ORC1 (244-

17 511) showed a significant increase in TIF-positive cells compared with the control (Figure 6E; HU).

18 These results further support the notion that TRF2-mediated ORC binding to telomeres contributes to

19 telomere stability upon DNA replication stress. 
bioRxiv preprint doi: https://doi.org/10.1101/2021.02.08.430303; this version posted February 8, 2021. The copyright holder for this preprint (which was not certified by peer review) is the author/funder, who has granted bioRxiv a license to display the preprint in perpetuity. It is made available under aCC-BY 4.0 International license.

A

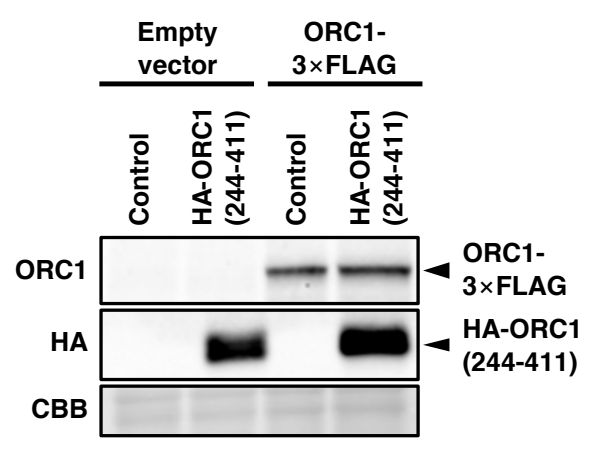

D

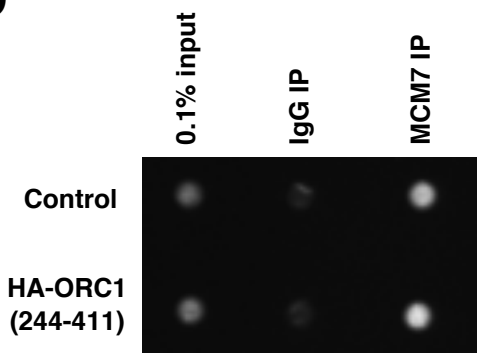

B
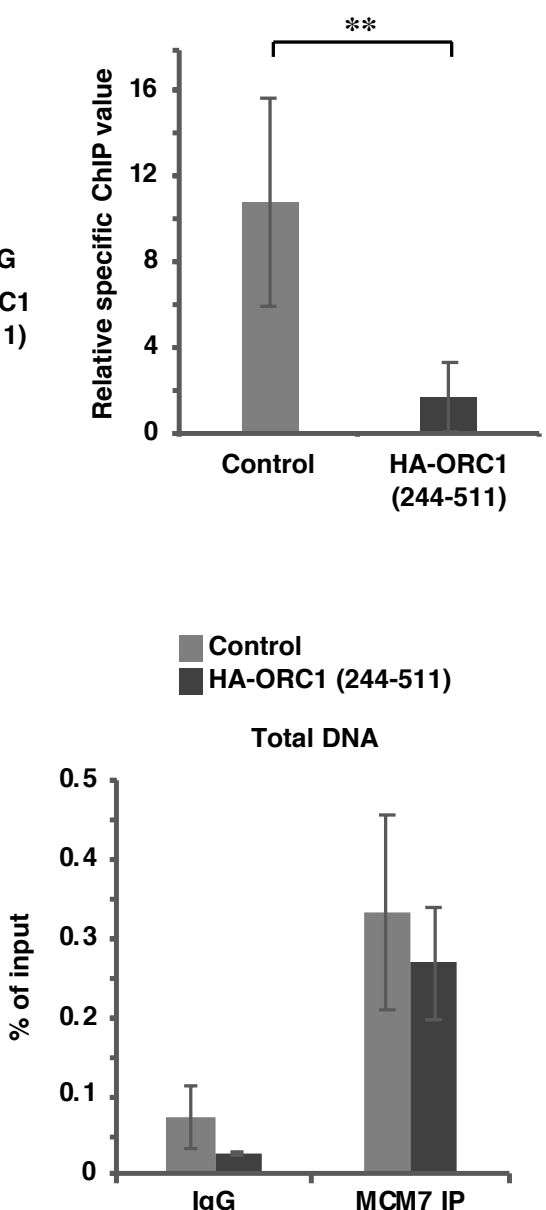

C Control

HA-ORC1 (244-511)

Telomere DNA

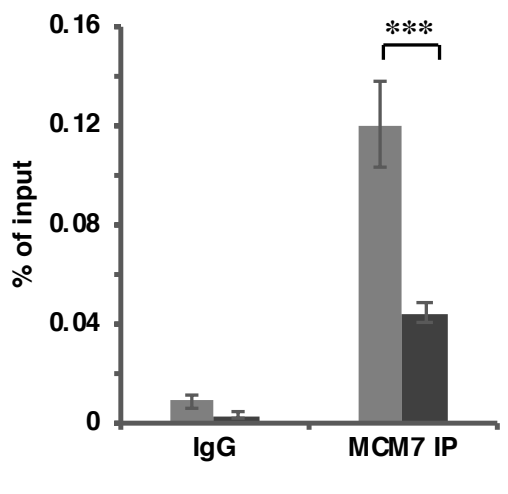

$\mathbf{E}$

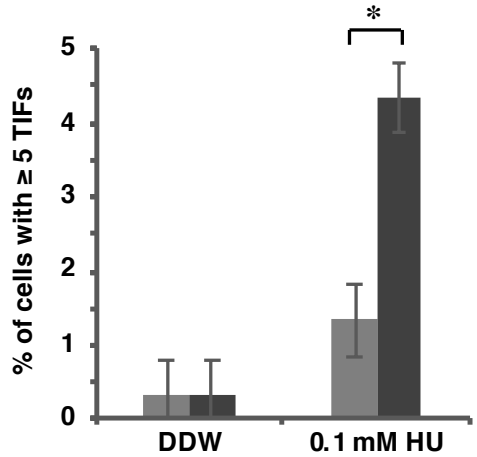

Figure 6. Overexpression of an ORC1 (244-511) fragment inhibits ORC- and MCM-binding to telomeres and exacerbates the accumulation of 53BP1 at telomeres upon replication stress.

(A and B) Control and HA-ORC1 (244-511)-overexpressing HeLa cells were transfected with empty vector or ORC1-3 $\times$ Flag expression vector. At $48 \mathrm{~h}$ post-transfection, cells were subjected to ChIP with anti-FLAG antibody. (A) Cell lysates for ChIP assay were subjected to immunoblotting with the indicated antibodies. CBB serves as a loading control. (B) Purified DNAs from input and IPs were analyzed by qPCR with a primer pair amplifying a telomeric sequence or the $L M N B 2$ replication origin. Relative specific ChIP values were calculated as described in Figure $2 E$. The means \pm SDs are shown $(n=6) . * *, P<0.01$ (two-tailed Student's $t$-test). (C and D) Cells were subjected to the ChIP assay with control IgG or anti-MCM7 antibody. (C) Purified DNAs from input and IPs were analyzed by qPCR with a primer pair amplifying a telomeric sequence. Results are shown as the percent of input DNA. The means \pm SDs are shown $(n=6) .{ }^{* * *}, P<0.001$ (two-tailed Student's $t$-test). (D) Left, the total amounts of coprecipitated DNA and input DNA were analyzed using SYBR Gold staining and UV photography. Right, the means \pm SDs are shown $(n=2)$. (E) Cells were treated with $0.1 \mathrm{mM}$ hydroxyurea $(\mathrm{HU})$ for $16 \mathrm{~h}$. Telomere foci co-localizing with 53BP1 were analyzed as in Figure $3 A$ and $B$. The frequency of cells carrying $\geq 5$ TIFs was scored. The means \pm SDs are shown $(n=3)$. One hundred cells were analyzed for each sample. The sum scores are used for statistical analyses. ${ }^{*}, \mathrm{P}<0.05$ (Fisher's exact test). 
A

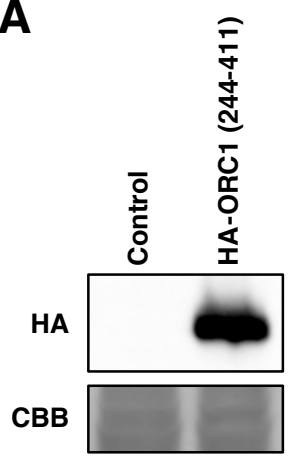

B

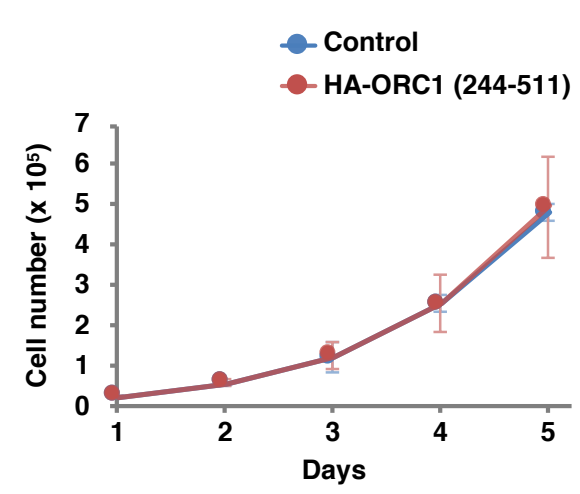

C

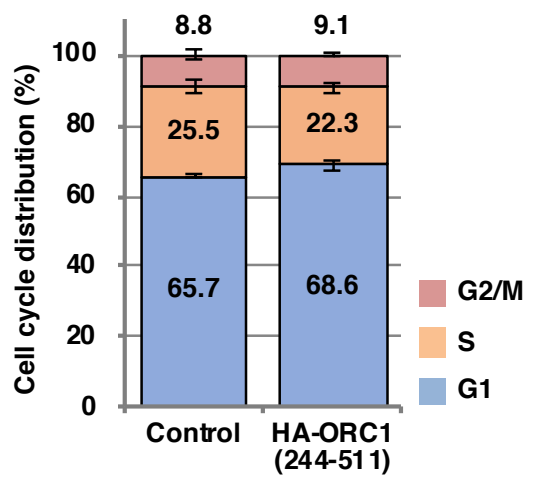

Figure 6-figure supplement 1. Overexpression of an HA-ORC1 (244-411) fragment does not affect HeLa cell proliferation. (A) HeLa cells stably expressing HA-ORC1 (244-411) fragment were established by retroviral infection. Expression of the introduced protein was analyzed by immunoblotting with anti-HA antibody. CBB serves as a loading control. (B) The cell growth was investigated for five days. The means \pm SDs are shown $(n=2)$. (C) The cell cycle was analyzed by flow cytometry. The means \pm SDs are shown $(n=2)$.

\section{ORC1-3xFlag ChIP - qPCR}
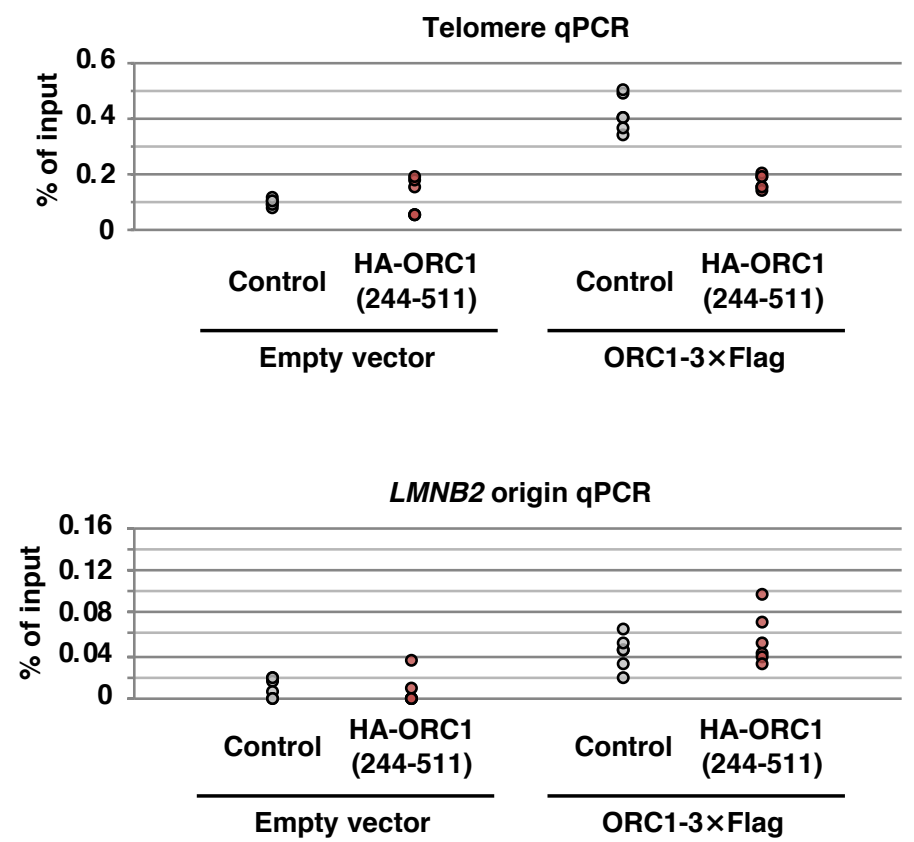

Figure 6-figure supplement 2. Source data of ChIP experiments. $\%$ of input values used for the calculation in Figure $6 \mathrm{~B}$ are shown. 
bioRxiv preprint doi: https://doi.org/10.1101/2021.02.08.430303; this version posted February 8, 2021. The copyright holder for this preprint (which was not certified by peer review) is the author/funder, who has granted bioRxiv a license to display the preprint in perpetuity. It is made available under aCC-BY 4.0 International license.

A

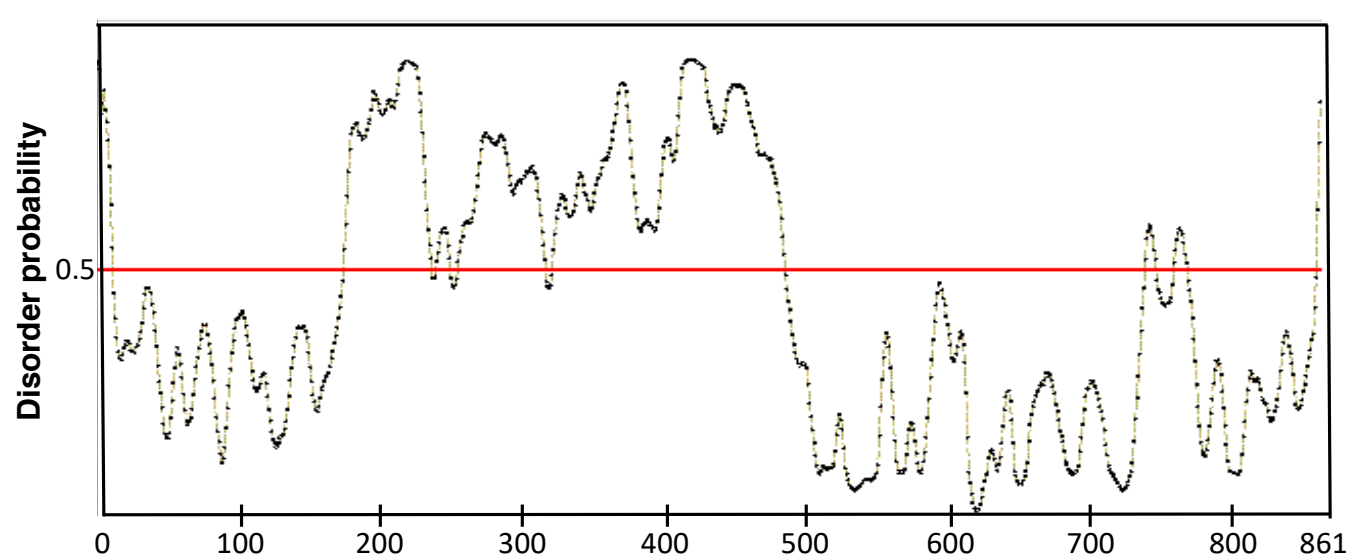

B

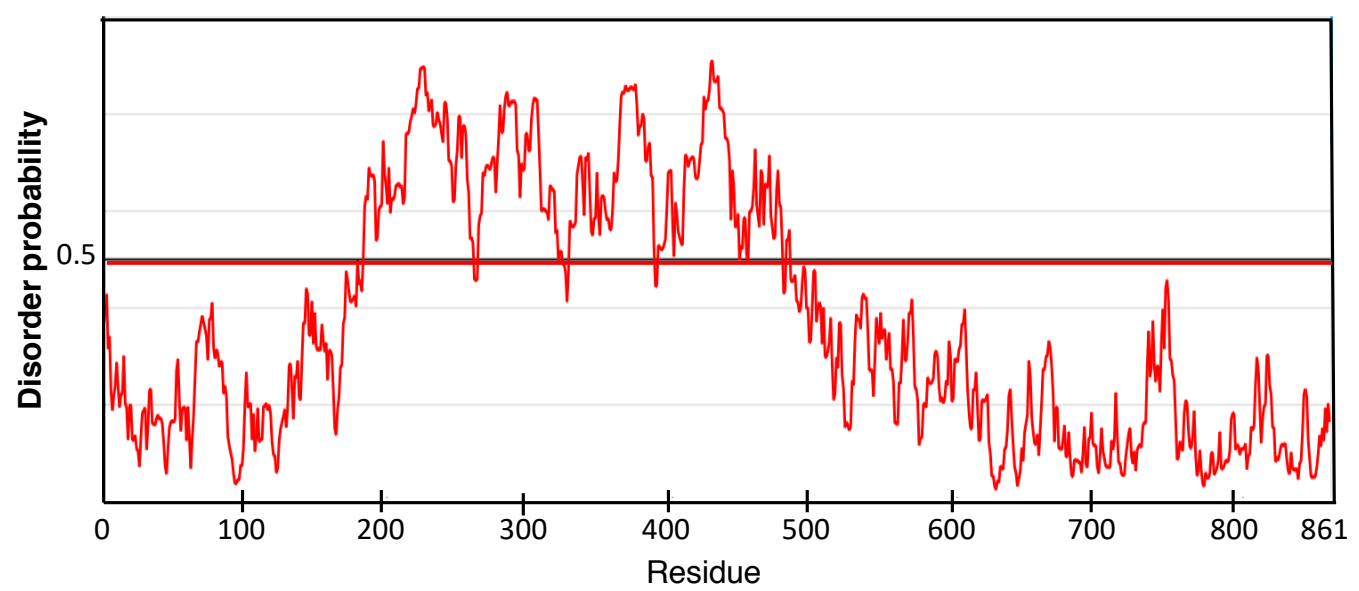

C

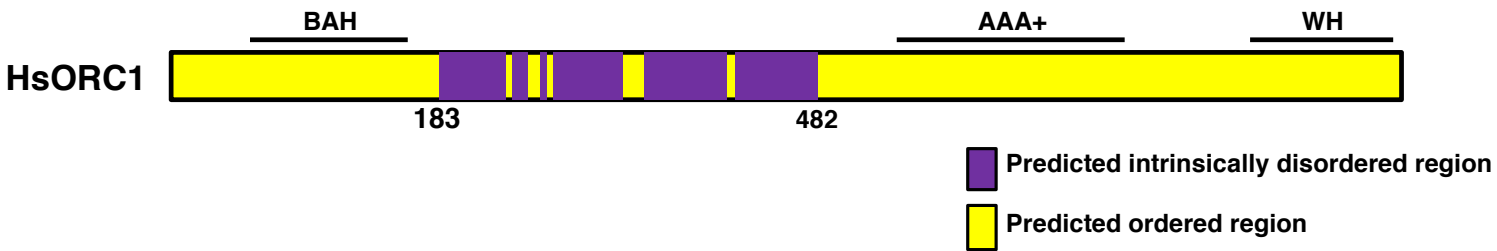

D Intrinsically disordered region

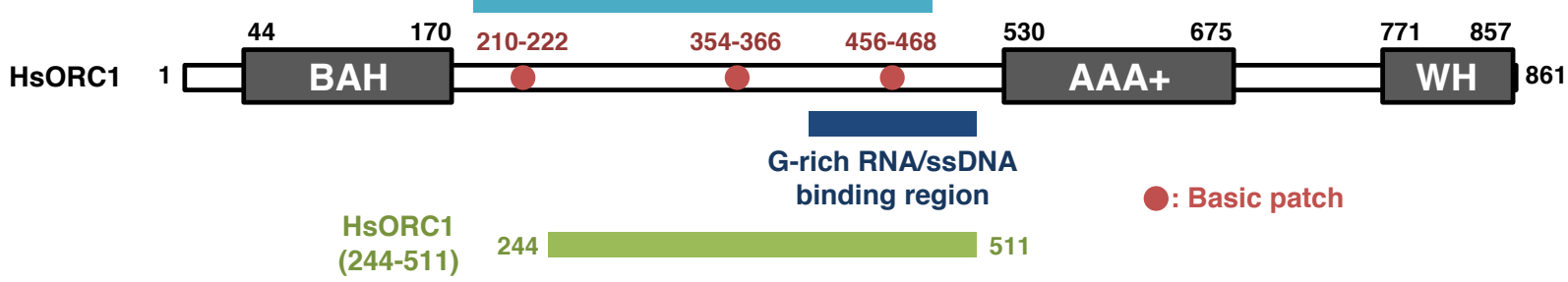

Figure 6-figure supplement 3. Schematics of ORC1 domain architecture showing the predicted intrinsically disordered region.

(A-C) Intrinsically disordered region in ORC1 was predicted by (A) PrDOS (Ishida and Kinoshita, 2007) or (B) IUPred2A (Mészáros et al., 2018). Predicted disorder probability is plotted. Red horizontal line represents the disorder/order threshold (a cutoff value 0.5 ) and residues scored above the line are predicted to be disordered. (C) Schematics of the intrinsically disordered region in ORC1. Purple rectangles represent overlapping regions of disorder predicted by each server. (D) Schematics of the full-length human ORC and ORC1 (244-511) fragments used in this study. BAH, bromo adjacent homology domain; AAA+, ATPases associated with diverse cellular activities domain; $\mathrm{WH}$, winged-helix domain.

References:

1. T. Ishida and K. Kinoshita (2007) PrDOS: Prediction of disordered protein regions from amino acid sequence. Nucleic Acids Res. 35: W460-W464.

2. B. Mészáros, G. Erdős, and Z. Dosztányi (2018) IUPred2A: Context-dependent prediction of protein disorder as a function of redox state and protein binding. Nucleic Acids Res. 46: W329-W337. 


\section{Discussion}

2 In this study, we specifically inhibited the TRF2-ORC interaction using the TRF2 E111A/E112A

3 mutant, which is specifically defective for ORC1 binding (Figure 1). In HeLa TRF2 E111A/E112A

4 knock-in clones, the recruitment of ORC and MCM to telomeres was reduced, and replication-stress-

5 induced telomere instability was significantly enhanced (Figures 2 and 3). As an alternative

6 experimental system, we identified an ORC1 fragment (244-511), which competitively inhibits the

7 TRF2-ORC interaction. When this fragment was overexpressed in human cells, levels of telomere-

8 bound ORC and MCM were reduced and replication stress-induced telomere DNA damage was

9 enhanced (Figures 5 and 6). These specific inhibitions of the TRF2-ORC interaction avoid the

10 limitations of simple TRF2 knockdown studies (Deng et al., 2007; Tatsumi et al., 2008), which result

11 in the deprotection of telomere ends and prevent TRF2-binding factors from accessing telomeres.

12 Our findings indicate a critical role for the TRF2-ORC interaction in the recruitment of ORC and

$13 \mathrm{MCM}$ to telomeres and in the maintenance of telomere stability. It has recently been demonstrated

14 that overexpression of a TRF2 $\triangle \mathrm{B}$ mutant, an ORC-binding mutant that lacks the N-terminal basic

15 domain (Atanasiu et al., 2006; Deng et al., 2007), decreases ORC recruitment to telomeres and leads

16 to telomere fragility in LOX human melanoma cells (Drosopoulos et al., 2020). However,

17 overexpression of TRF2 $\triangle \mathrm{B}$ also induces cell cycle arrest, senescence, and rapid loss of telomeres

18 (Deng et al., 2007; Drosopoulos et al., 2020; Saint-Léger et al., 2014; van Steensel et al., 1998; Wang

19 et al., 2004). These phenotypes may be a consequence of the multiple roles the TRF2 basic domain

20 has been shown to play in preventing homologous recombination-mediated telomere deletion (Poulet

21 et al., 2009; Rai et al., 2016; Saint-Léger et al., 2014; Wang et al., 2004), promoting the replication of

22 heterochromatin (Mendez-Bermudez et al., 2018), and mediating ORC recruitment at telomeres.

23 The dimerization of the TRF2 TRFH domain is required for the TRF2-ORC interaction (Higa et

24 al., 2017b). Moreover, the TRF2 E111/E112 residues are critical for ORC recruitment (Figure 1).

25 Our data suggest that the SLX4-binding region of TRF2 overlaps with the ORC1-binding region within 
the TRFH domain, yet the TRF2 E111A/E112A mutant retains its ability to interact with SLX4 while

2 losing the ability to bind ORC (Figure 1B and 1F). In addition, the Y73, G74, V88, P90, K93, E94,

$3 \mathrm{H} 95, \mathrm{~T} 96, \mathrm{~S} 119$, and M122 residues are also involved in ORC recruitment. The involvement of these

4 residues, which are widely distributed, suggests that TRF2 and ORC1 interact through a broad binding

5 interface. Indeed, we found that, although ORC1 (325-511) is sufficient for TRF2 binding, ORC1

6 (244-511) co-localizes with TRF2 with a 2-fold higher frequency (Figure 4). A flexible linker

7 sequence is present between the $\mathrm{N}$-terminal $\mathrm{BAH}$ (bromo adjacent homology) domain and the C-

8 terminal AAA+ domain of ORC1 (Figure 6-figure supplement 3). This region is predicted to be a

9 conserved, intrinsically disordered region (Figure 6-figure supplement 3) (Parker et al., 2019).

10 Therefore, multiple residues in the ORC1 244-511 region may form a flexible binding interface for

11 the interaction with TRF2.

12 Our results further reveal that TRF2 Y73A/G74A, V88A/P90A, E111A/E112A, and

13 S119A/M122A mutations have no obvious effect on TRFH dimerization or the ability of TRF2 to bind

14 Apollo, RAP1 or RETL1 (Figure 1C-E and G). TRF2 F120 is particularly important for the

15 interaction with Apollo and SLX4 through their shared F/Y/HxLxP motif (Chen et al., 2008; Wan et

16 al., 2013). RTEL1 binds to both TRF2 amino acids 64-83 and 312-341, with I79 playing a

17 particularly crucial role in RTEL1 binding (Sarek et al., 2019, 2015). A RAP1-binding motif is found

18 at the TRF2 275-316 region (Chen et al., 2011). The present data are in line with these findings.

19 Although the TRF2 S119A/M122A mutations are in the proximity of F120, this mutant interacts with

20 Apollo and SLX4, but not ORC1, suggesting that the TRF2 residues responsible for the bindings are

21 different among these factors.

ChIP analysis revealed that ORC and MCM loading at telomeres is reduced by the

23 overexpression of ORC1 (244-511) (Figure 6). Importantly, ORC1 (244-511) overexpression did

24 not affect genome-wide DNA binding of MCM (Figure 6D), suggesting that ORC1 (244-511)

25 overexpression selectively impairs the telomere binding activity of ORC. Moreover, re-replication 
1 induced by co-expression of Cdt1+ORC1 was not compromised by overexpression of ORC1 (244-

2 511). The formation of the ORC complex should be unaffected by ORC1 (244-511) overexpression

3 since the ORC1 N-terminal region (amino acids 1-470) is not essential for ORC complex formation

4 (Tocilj et al., 2017). The BAH domain of ORC1 recognizes histone H4-K20me2 and regulates the

5 loading of ORC onto replication origins, while mutations in this domain are implicated in the etiology

6 of Meier-Gorlin syndrome (Beck et al., 2012; Bicknell et al., 2011; Kuo et al., 2012). The ORC1

$7 \quad 244-511$ region is situated away from the BAH domain and is unlikely to affect BAH domain-mediated

8 binding to replication origins. The ORC1 244-511 region does, however, overlap with basic patches

9 and G-rich RNA/ssDNA binding regions (Bleichert et al., 2018; Hoshina et al., 2013; Li et al., 2018)

10 (Figure 6-figure supplement 3) thought to be involved in the interaction with origin DNA. It is

11 possible that the binding of DNA through these regions of ORC1 is affected by ORC1 (244-511)

12 overexpression. Future studies are required to evaluate the contribution of these regions to ORC

13 recruitment to the G-rich telomere repeat sequence.

14 Dormant replication origins are critical for complete duplication of the genome (Alver et al.,

15 2014; Moreno et al., 2016). A paucity of backup replication origins results in chromosome instability

16 (Chuang et al., 2010; Ibarra et al., 2008; Kawabata et al., 2011; Shima et al., 2007). It has been

17 reported that dormant telomeric origins are activated by replication stress to complete telomere

18 replication (Drosopoulos et al., 2020). Our findings support the view that TRF2-mediated ORC and

19 MCM recruitment plays a pivotal role in maintaining telomere stability through the formation of

20 dormant telomeric origins that fire when replication forks stall or collapse. 


\section{Materials and Methods}

\section{Cell culture}

3 U2OS, U2OS 2-6-3 (Higa et al., 2017b; Janicki et al., 2004), HEK293T, HeLa, TRF2-edited HeLa 4 clones, and HCT116 cells were maintained in Dulbecco's modified Eagle's medium (Wako) supplemented with $8 \%$ fetal calf serum and antibiotics $(0.1 \mathrm{mg} / \mathrm{ml}$ kanamycin).

\section{Plasmids}

8 pSV40-HA-LacI, pSV40-TRF2-LacI, pSV40-TRF2 (45-244)-LacI, pSV40-TRF2 2 Myb-LacI, 9 pcDNA3.1-zeo-ORC1-3×FLAG, pCLMSCV-HA-TRF2, and pCLMSCVhyg-T7-Cdt1 were described 10 previously (Higa et al., 2017b; Sugimoto et al., 2008; Tatsumi et al., 2008, 2003).

pcDNA3.1-zeo-ORC1 (L229A)-3×FLAG, pcDNA3.1-zeo-ORC1 (D620A)-3×FLAG, pSV40-

12 TRF2 (45-244/Y73A/G74A)-LacI, pSV40-TRF2 (45-244/V88A/P90A)-LacI, pSV40-TRF2 (45-

13 244/K93A/E94A/H95A/T96A)-LacI, pSV40-TRF2 (45-244/S98A/R102A)-LacI, pSV40-TRF2 (4514 244/E111A/E112A)-LacI, pSV40-TRF2 (45-244/S119A/M122A)-LacI, pENTR4-HA-TRF2 15 (Y73A/G74A), pENTR4-HA-TRF2 (V88A/P90A), pENTR4-HA-TRF2 (K93A/E94A/H95A/T96A), 16 pENTR4-HA-TRF2 (S98A/R102A), pENTR4-HA-TRF2 (E111A/E112A), and pENTR4-HA-TRF2 17 (S119A/M122A) were produced by oligonucleotide-directed mutagenesis (Quick Change Site18 directed Mutagenesis Kit; Stratagene) with the following mutagenic oligonucleotides and their 19 complement.

cDNA

ORC1 (L229A)

ORC1 (D620A)

TRF2 (Y73A/G74A)

TRF2 (V88A/P90A)

TRF2 (K93A/E94A/

H95A/T96A)

27

28

29

30
Mutagenic oligonucleotide

5'- CCTACCCATCCTGCTACCCCGCGCGCCAGAAAGAGGC -3'

5'- CGTCCTGCTTGTGGCTGAGCTCGACC -3'

5'- GCGCGCATTTCGCGGATCCCGCGCTGCTGACTTCCGC -3'

5'- CTCTGCTGGCGCGCGCACTGGGCAAAG -3'

5'- GCCCACTGGGCGCTGCAGCTGCCGTGTCCCGCCTGC -3'

5'- CATACCGTGGCGCGCCTGCTGGCCGTGATGCAG -3'

5'- GCCGCATTGCAGCCGGCGAAAACCTGGAC -3'

5'- CCTGGACTGTGCCTTTGATGCGGAAGCTGAGCTGACCCCACTGG -3'

pAAVS1-CMV-HA-TRF2 and variants encoding alanine-substitution mutants of TRF2 (used in Figure 1E-G) were prepared using the In-Fusion (Clontech) reaction. The cDNAs were amplified by PCR with the primers listed below with a series of pENTR-HA-TRF2 vectors as template DNA. 
1 BglII- and SalI-digested pAAVS1-CMV (provided by Dr. Kanemaki, National Institute of Genetics,

2 Mishima; Addgene \# 105924) (Okumura et al., 2018) was used as the backbone vector.

PCR primer

pAAVS1 series 5'- GGACTCAGATCTGCCACCATGTACCCC -3'

5'- GGTACCGTCGACTTAGTTCATACCCAGGCG -3'

pFLAG-CMV-6a-Apollo was generated as follows: the cDNA was amplified by PCR from the template vector pCMV-SPORT6-Apollo (purchased from Dharmacon, clone\# 5001181) using the primers listed below. Amplified cDNA and pFLAG-CMV-6a (SIGMA-ALDRICH) were digested by HindIII and PstI, and ligated using the Takara Ligation Kit (Takara, 6023).

CDNA PCR primer

Apollo 5'- CTCAAGCTTGACTCCAACCCTACC - $3^{\prime}$

5'- ATCCTGCAGGTTGTCATTCTGTACTCTCC -3'

pFLAG-CMV-6a-SLX4 was generated as follows: the cDNA was amplified from pcDNAFRT/TO GFP-BTBD12 (provided by Dr. Dario Alessi, University of Dundee, Scotland; clone number DU19216) (Muñoz et al., 2009) using the primers listed below. Amplified cDNA and HindIIIdigested pFLAG-CMV-6a were subjected to the In-Fusion reaction.

CDNA PCR primer

SLX4 5'- CGACAAGCTCAAGCTTAAACTCAGTGTGAATGAGGCTC -3' 5'- TCGCGGCCGCAAGCTTCAGTTCCGCTCCACCT -3'

pFLAG-CMV-6a-ORC1 was prepared as follows: pBluescript-ORC1 (Fujita et al., 2002) was partially digested by NcoI, and a $5.5 \mathrm{kbp}$ fragment was purified by agarose gel electrophoresis and gel extraction. After blunting using the Klenow fragment (Takara, 2140A), the fragment was further digested with NotI and ScaI, and a $2.4 \mathrm{kbp}$ ORC1 fragment was purified by agarose gel electrophoresis and gel extraction. pFLAG-CMV-6a was digested with HindIII followed by blunting with the Klenow fragment, and further digested with NotI. After de-phosphorylation of the linear vector using Shrimp Alkaline Phosphatase (Takara, 2660A), the cDNA and the linear vector were mixed and ligated.

pX459-terf2-exon2-1 was generated by inserting a synthesized oligonucleotide into the pX459 vector (a gift from Feng Zhang, Broad Institute, Cambridge, MA; purchased from Addgene, \# 62988) (Ran et al., 2013). To prepare the insert, the oligonucleotides listed below were mixed at final concentration of $4.5 \mu \mathrm{M}$ each in $1 \times$ annealing buffer $\left[20 \mathrm{mM}\right.$ Tris- $\mathrm{HCl} \mathrm{pH} 7.5,5 \mathrm{mM} \mathrm{MgCl}_{2}, 30 \mathrm{mM}$ 
$1 \mathrm{NaCl}$, and $1 \mathrm{mM}$ dithiothreitol (DTT)]. Mixed oligonucleotides were annealed by incubation at

$2 \quad 100^{\circ} \mathrm{C}$ for $5 \mathrm{~min}$ followed by cooling at room temperature, and then phosphorylated by $\mathrm{T} 4$ 3 polynucleotide kinase (Takara, 2021S). pX459 was digested with BbsI. Annealed oligonucleotides

4 and linear vectors were mixed and ligated.

oligonucleotides for insert DNA

5'- CACCGGGGTTATGCAGTGTCTGTCG -3'

5'- AAACCGACAGACACTGCATAACCCC -3'

pFLAG-CMV-6a-ORC1 (2-511), pFLAG-CMV-6a-ORC1 (2-325), pFLAG-CMV-6a-ORC1 (2-244), and pFLAG-CMV-6a-ORC1 (2-85) were prepared by self-ligation of pFLAG-CMV-6aORC1 digested with the following restriction enzymes.

ORC1 (2-511) EcoRI

ORC1 (2-325)

BspT104I*

EcoRV

ORC1 (2-244)

BstPI *

EcoRV

*, after digestion, ends were blunted using the Klenow fragment (Takara, 2140A).

pFLAG-CMV-6b-ORC1 (244-511) and pFLAG-CMV-6b-ORC1 (325-511) were prepared as follows: pFLAG-CMV-6a-ORC1 was digested with BstPI [for ORC1 (244-511)] or BspT104I [for ORC1 (325-511)], blunted with the Klenow fragment, and further digested with EcoRI. pFLAGCMV-6b (SIGMA-ALDRICH) was digested with HindIII, blunted with the Klenow fragment, and further digested with EcoRI. After de-phosphorylation of the linear vector using Shrimp Alkaline

Phosphatase, the truncated ORC1 cDNA and the linear vector were mixed and ligated.

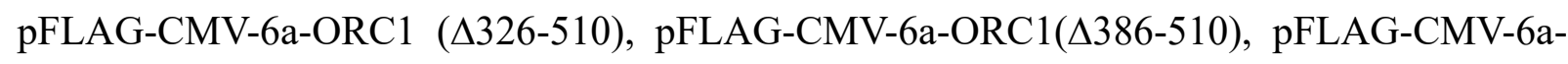
ORC1 ( $\Delta 411-510)$, pFLAG-CMV-6a-ORC1 ( $\Delta 446-510)$, and pFLAG-CMV-6a-ORC1 ( $\Delta 411-445)$ were prepared as follows: two fragments of ORC1 cDNA were amplified by PCR with the primers listed below using pcDNA3.1-zeo-ORC1-3×FLAG as a template. Amplified cDNA fragments and HindIII-digested pFLAG-CMV-6a were subjected to the In-Fusion or NEBuilder reaction (New England BioLabs, E2621). 


$$
\text { 2: ORC1 (511-861) }
$$

$\operatorname{ORC1}(\Delta 386-510) \quad 1: \operatorname{ORC} 1(2-385)$

2: ORC1 (511-861)

$\operatorname{ORC1}(\Delta 411-510) \quad$ 1: ORC1 (2-410)

2: ORC1 (511-861)

$\operatorname{ORC1}(\Delta 446-510) \quad 1:$ ORC1 (1-445)

2: ORC1 (511-861)

$\operatorname{ORC1}(\Delta 411-445) \quad$ 1: ORC1 (2-410)

2: ORC1 (446-861)
5'- TTCCAAGACATCTACAATTTTG -3'

5'- GAATTCGCGGCCGCATTACTCGTCTTTCAGCG -3'

5'- GATGACGACAAGCTCAAGCTTGCACACTACCCCACAA -3'

5' - CAAAATTGTAGATGTCTTGGAAGACAGAACTCTTTCTGC -3'

5'- TTCCAAGACATCTACAATTTTG -3'

5'- TGAATTCGCGGCCGCAAGCTTTACTCGTCTTTCAGCGC -3'

5'- GATGACGACAAGCTCAAGCTTGCACACTACCCCACAA -3'

5'- CAAAATTGTAGATGTCTTGGAAAATCTCTTTCTCTTCTTGGTC-3'

5'- TTCCAAGACATCTACAATTTTG -3'

5'- TGAATTCGCGGCCGCAAGCTTTACTCGTCTTTCAGCGC -3'

5'- CGATGACGACAAGCTCATGGCACACTACCCC -3'

5'- CAAAATTGTAGATGTCTTGGAAAGATCGCAGGTTCCTG -3'

5' - TTCCAAGACATCTACAATTTTG -3'

5'- GAATTCGCGGCCGCATTACTCGTCTTTCAGCG -3'

5'- GATGACGACAAGCTCAAGCTTGCACACTACCCCACAA -3'

5'- TGTAAGGATGACTTCAAGGAAATCTCTTTCTCTTCTTGGTC -3'

5'- TCCTTGAAGTCATCCTTACATAC -3'

5'- TGAATTCGCGGCCGCAAGCTTTACTCGTCTTTCAGCGC -3'

The retroviral expression vector pQCXIP-HA-ORC1(244-511) was prepared by In-Fusion reaction. The cDNAs were amplified by PCR with the primers for N-terminal HA-tagging listed below using pcDNA3.1-zeo-ORC1-3×FLAG as template DNA. NotI-digested pQCXIP (Clontech) was used as the backbone vector.

CDNA PCR primer

HA-ORC1(244-511)

5'- AATTGATCCGCGGCCGCCACCATGTACCCCTACGATGTGCCCGATTACGCC

AACCCTCAGATGTCCCAGC $-3^{\prime}$

5'- CCTACCGGTGCGGCCTTAGAATTCCTGTTCCCGACAGG -3'

As described previously (Higa et al., 2017b; Tatsumi et al., 2008), our TRF2 cDNA was chemically synthesized with codon optimization and thus some oligonucleotide sequences described here are not comparable to those of cell-derived TRF2 cDNA. The length of our TRF2 oligopeptide is 500 amino acids, which is 42 amino acids shorter at the N-terminus (542 amino acids in total) than that used in studies of the RTEL1-binding regions of TRF2 (Sarek et al., 2019, 2015). Therefore, the apparent position of residues differ between these studies. 


\section{Transfection}

3 For immunofluorescence analysis, expression plasmids (total: $0.56 \mu \mathrm{g}$ for Figs. 1B, 1D, 4B, 4D; 0.84 $4 \mu \mathrm{g}$ for Fig. 5B) were transiently transfected into $8 \times 10^{4}$ U2OS 2-6-3 cells in 4-well chamber slides 5 using Lipofectamine 2000 reagent (Invitrogen, 11668019) according to the manufacturer's instructions.

For immunoprecipitation, ChIP and re-replication analysis, transfection was performed with PEImax reagent (Polysciences, 24765), as previously described (Sugimoto et al., 2015). Detailed transfection conditions used in the experiments are listed below. For ChIP analysis (Figures 2E, F, and $6 \mathrm{~A}, \mathrm{~B})$, the medium was changed $6 \mathrm{~h}$ after transfection.

\section{Immunofluorescence staining}

21 For Figure 1B, co-staining of endogenous ORC1 with LacI were performed as described previously (Higa et al., 2017b). Briefly, cells were washed with PBS (Wako, 048-29805), fixed with chilled $100 \%$ methanol for $10 \mathrm{~min}$, permeabilized with $0.1 \%$ Triton X-100 in PBS for $10 \mathrm{~min}$, and then immunostained.

For the staining of FLAG-Apollo, and FLAG-ORC1 truncation mutants (Figures 1D and 4B), cells were fixed with 3.7\% formaldehyde (Nacalai Tesque, 16223-55) in PBS. For the staining of fulllength FLAG-ORC1 and FLAG-ORC deletion mutants (Figures 4D and 5B), cells were fixed with chilled $100 \%$ methanol for $10 \mathrm{~min}$, and permeabilized with $0.1 \%$ Triton X-100 in PBS for $10 \mathrm{~min}$. The staining of 53BP1 was performed after PNA-FISH (Figures 3A, B and 6E). Cells were then incubated with primary antibodies in PBS supplemented with $1 \%$ fetal calf serum for $1 \mathrm{~h}$ at room temperature for $53 \mathrm{BP} 1$ staining or $2 \mathrm{~h}$ at $37^{\circ} \mathrm{C}$ for LacI co-staining, followed by incubation with secondary antibody for $1 \mathrm{~h}$ at room temperature and $0.2 \mu \mathrm{g} / \mathrm{ml} 4$,6-diamidino-2-phenylindole (DAPI) in PBS for $15 \mathrm{~min}$ at room temperature. Cells were washed three times after each staining with PBS 
1 for $5 \mathrm{~min}$ at room temperature, and finally mounted in Fluoro-KEEPER Antifade Reagent (Nacalai 2 Tesque, 12593-64) and stored at $4^{\circ} \mathrm{C}$.

Microscopic analysis was performed with the KEYENCE BZ-9000 or BZ-X700 fluorescence microscope. Co-localization frequency of foci of each protein with the LacI foci was examined. A summary of the co-localization frequency calculated from multiple biologically independent experiments is shown in the figures. The values are sum scores from at least two independent experiments performed for each condition. At least 31 cells with a prominent LacI focus were scored

8 for each experiment/condition.

\section{Immunoprecipitation}

11 For Figure 1C, E and F, cells were lysed in $500 \mathrm{mM} \mathrm{NaCl}$ NET gel buffer (500 mM NaCl, 0.1\% Triton $12 \mathrm{X}-100,50 \mathrm{mM}$ Tris- $\mathrm{HCl} \mathrm{pH}$ 7.4). The lysates were diluted with $0 \mathrm{M} \mathrm{NaCl}$ NET gel buffer to a final $13 \mathrm{NaCl}$ concentration of $150 \mathrm{mM}$ and then subjected to immunoprecipitation with $2 \mu \mathrm{g}$ antibody. 14 Bound proteins were eluted in $1 \times$ sample buffer $(62.5 \mathrm{mM}$ Tris-HCl pH 6.8, 2\% SDS, 5\% 215 mercaptoethanol, 10\% glycerol, $0.01 \%$ bromo- phenol blue).

For Figures $1 \mathrm{G}$ and 5A, transfected HEK293T cells were cross-linked with 1\% formaldehyde and then subjected to immunoprecipitation as described previously (Higa et al., 2017b) using $2 \mu \mathrm{g}$ (Fig. $1 \mathrm{G})$ or $4 \mu \mathrm{g}$ (Fig. 5A) of antibody.

\section{Immunoblotting and antibodies}

21 Immunoblotting was performed as described previously (Sugimoto et al., 2008). Coomassie brilliant 22 blue (CBB) staining was performed with the Rapid Stain CBB Kit (Nacalai Tesque, 30035-14). 23 Quantification was performed with the LumiVision Analyzer (for immunoblots, AISIN Seiki) or 24 ImageJ software (for CBB, NIH).

Preparation of polyclonal rabbit antibodies against human ORC1, Cdt1 and MCM7 was described previously (Tatsumi et al., 2008). Rabbit anti-LacI antibody was obtained by immunizing rabbits with a bacterially produced His-T7-LacI protein.

Other antibodies used in this study are as follows: LacI (clone 9A5, Merck, 05-503), ORC1 30 (clone M2, SIGMA-ALDRICH), FLAG-tag (Thermo, PA1-984B), RAP1 (Bethyl, A300-306A), 31 RTEL1 (Novus, NBP2-22360), SLX4 (Novus, NBP1-28680), TRF2 (Merck, 4A794), 53BP1 (Novus, 32 NB100-904), rabbit normal IgG (DAKO, X0903), mouse normal IgG (Southern Biotech, 0107-01), 33 horseradish-peroxidase (HRP)-conjugated anti-mouse IgG (H + L) (Invitrogen, 61-6520 or 34 ROCKLAND, 18-8817-33), HRP-conjugated anti-rabbit IgG (H + L) (Invitrogen, 65-6120 or 
ROCKLAND,18-8816-33), HRP-conjugated anti-rat IgG (H + L) (Zymed, 62-9520), CF488Aconjugated goat anti-rabbit IgG (Biotium, 20019), CF594-conjugated donkey anti-rabbit IgG (Biotium 20152), CF594-conjugated goat anti-mouse IgG (Biotium, 20111), Alexa488-conjugated goat anti4 mouse IgG (Invitrogen, A11029).

6 Cas9-based gene-editing

7 Cas9-based gene-editing was performed by transient transduction of Cas9/guide RNA and ssODN 8 (Ran et al., 2013). HeLa cells cultured in 6 well plates $\left(1 \times 10^{5} /\right.$ well) were co-transfected with $2 \mu \mathrm{g}$ 9 pX459-terf2-exon2-1 and $2 \mu \mathrm{g}$ ssODN using Lipofectamine 2000 reagent. ssODN carries the following sequence: SsODN WT,

$5^{\prime}-$

11 AGAGAAGAACACAAAAATAGCCATACCTAAATTTTCCCCTTCTTCAATTCGCGACAGACA 12 CTGCATAACCCGCAGCAATCGGGACACGGT $\quad-3^{\prime} ; \quad$ ssODN $\quad$ EE, 13 AGAGAAGAACACAAAAATAGCCATACCTAAATTTTCCCCTGCTGCAATTCGCGACAGACA 14 CTGCATAACCCGCAGCAATCGGGACACGGT-3’.

After puromycin $(0.5 \mu \mathrm{g} / \mathrm{ml})$ selection for 3 days, cells were subjected to limiting dilution. Aliquots of the obtained clones were re-seeded into 96-well plates, and clones were screened by RFLP analysis. Positive clones were re-subjected to further limiting dilution. After the second selection, confirmed positive clones by RFLP analysis were used for subsequent experiments.

\section{RFLP analysis}

For screening of HeLa clones, cells were seeded into 96-well plate and rinsed with PBS once after reaching confluence. Forty-five microliters of $50 \mathrm{mM} \mathrm{NaOH}$ were then added to each well, and the cells were lysed in a $90-95^{\circ} \mathrm{C}$ water bath. Cell lysates were directly added to the PCR reaction mix 24 (Toyobo, KOD-201). with RNase A (Invitrogen) and proteinase K (Roche, 3115887001). Genomic DNA was precipitated by isopropanol (Nacalai tesque, 29113-95). Purified genomic DNA was dissolved in TE (10 mM Tris$\mathrm{HCl} \mathrm{pH} 8.0$ and $1 \mathrm{mM}$ EDTA) and fragmented by incubation at $70^{\circ} \mathrm{C}$ for $2-4 \mathrm{~h}$.

The following primers were used to amplify the target site in TERF2 gene exon 2: 5'GGACTTCAGACAGATCCGGG -3' and 5'- CTCCTCAGATACGAGTGGCAAG -3'. Amplified 32

33 Sequencing of the target locus of the TERF2 gene 
1 The target sites in the TERF2 gene exon2 were amplified as described above. For TA cloning, the

2 PCR products were 1000-fold diluted and re-amplified with Taq polymerase (Bioacademia, 02-001)

3 and the same primer pair. The products were purified by agarose gel extraction, cloned into T-Vector 4 pMD20 (Takara, 3270), and sequenced (Thermo, 4337454). Eleven colonies from each clone were analyzed.

\section{Chromatin immunoprecipitation and quantitative real-time PCR (qPCR) analysis}

8 Chromatin immunoprecipitation was performed as described previously (Ishimoto et al., 2021). For 9 qPCR analysis, SYBR Premix Ex Taq II (Takara, RR081A) or TB Green Premix Ex Taq II (Takara, 10 RR820A) was used according to the manufacturer's instructions. PCR reactions were performed using 11 the CFX96 Touch Real-Time PCR Detection System (BIO-RAD). For detection of the telomere 12 sequences and $L M N B 2$ replication origin region, the primer sequences and qPCR cycling parameters 13 were as described previously (Cawthon, 2002; Higa et al., 2017b; Sugimoto et al., 2011). The total 14 amount of co-precipitated DNA was quantified using SYBR Gold staining (Invitrogen, S11494) 15 (Sugimoto et al., 2015). SYBR Gold signals were captured using cooled-CCD camera detection systems (LumiVision Imager, AISIN Seiki) within the linear range, and band intensities were quantitated using LumiVision Analyzer.

\section{Fluorescence-activated cell sorting (FACS)}

Cells were trypsinized and suspended in PBS supplemented with $0.1 \%$ Triton X-100 and $10 \mu \mathrm{g} / \mathrm{ml}$ RNase A. After staining with propidium iodide $(40 \mu \mathrm{g} / \mathrm{ml})$, cell cycle distribution was examined using a FACS Verse flow cytometer (BD Bioscience) and ModiFit LT (Verity Software House). For Figure 5 D and E, re-replication was measured as described previously (Sugimoto et al., 2009). Dots with higher FL2-W signals, which result from aggregated cells and cell debris, were excluded from measurements of re-replication.

\section{PNA-FISH: fluorescence in situ hybridization with peptide nucleic acid probes}

After rinsing with PBS, cells were fixed with 3.7\% formaldehyde (for Figures 3A, B and 6E) or chilled $100 \% \mathrm{MeOH}$ (for Figure 3C and D). For formaldehyde fixation, cells were permeabilized in PBS containing $0.1 \%$ TX-100. Cells were dehydrated by incubating in serially diluted EtOH $(70 \%, 95 \%$, and 100\%). After drying cells completely, hybridizing solution [70\% formamide, $9 \mathrm{mM}$ Tris-HCl pH 7.5, 1\% skimmed milk, and $200 \mathrm{nM}$ Cy5-TelC (Panagene, F1003)] was added to each well. After placing coverslips onto slides, they were baked at $80^{\circ} \mathrm{C}$ for $5 \mathrm{~min}$, followed by incubation at room temperature overnight. After removing coverslips, cells were washed once with PBS, twice with washing solution $(70 \%$ formamide and $9 \mathrm{mM}$ Tris- $\mathrm{HCl} \mathrm{pH} \mathrm{7.5)} \mathrm{at} \mathrm{room} \mathrm{temperature} \mathrm{for} 15 \mathrm{~min}$, and 
1 three times with PBS. For co-staining with 53BP1, immunofluorescence staining was performed

2 after PNA-FISH.

4 Establishment of HeLa cells stably expressing HA-ORC1 (244-511)

5 HeLa cells were infected with the recombinant retroviruses encoding HA-ORC1(244-511) or an empty

6 vector, as described previously (Sugimoto et al., 2009). Infected cells were selected with puromycin

$7 \quad(0.5 \mu \mathrm{g} / \mathrm{ml})$ and subjected to assays without cloning.

\section{Data presentation and statistical analysis}

10 Unless otherwise stated, quantitative data are represented as the mean \pm SD of three or more 11 independent experiments. The number of experiments was chosen according to the standards of the 12 field. The statistical analyses used are defined in each figure legend. For Figures 1B, 1D, 3B, 4B, $134 \mathrm{D}, 5 \mathrm{~B}$, and $6 \mathrm{E}$, the sum scores of two or more independent experiments were used for the statistical 14 analyses. Individual values of each experiment are provided as Source data files. Only for Figure 15 4-figure supplement 1, the values represent the score from a single experiment. For the $t$-tests, data 16 distribution was assumed to be normal but this was not formally tested. Tukey-Kramer multiple 17 comparison test was performed after examination by one-way ANOVA. P-values less than 0.05 were 18 considered statistically significant. For qualitative data and semi-quantitative data, a representative 19 image from multiple independent experiments is shown; for all such figures, essentially the same 20 results were obtained in the multiple independent experiments.

\section{List of Figures, figure supplements, and source data}

23 Figure 1, Figure 1-source data 1

24 Figure 2, Figure 2-figure supplement 1, Figure 2-source data 1

25 Figure 3, Figure 3-source data 1

26 Figure 4, Figure 4-figure supplement 1, Figure 4-source data 1

27 Figure 5, Figure 5-figure supplement 1, Figure 5-source data 1

28 Figure 6, Figure 6-figure supplement 1, Figure 6-figure supplement 2, Figure 6-figure supplement 3, 29 Figure 6-source data 1 


\section{Acknowledgements:}

2 We thank Tohru Kiyono (National Cancer Center EPOC, Kashiwa), Masato Kanemaki (National

3 Institute of Genetics, Mishima), Yoko Katsuki (Kyoto University, Kyoto), Minoru Takata (Kyoto

4 University, Kyoto), Hilary McLauchlan (University of Dundee, Scotland), and John Rouse (University

5 of Dundee, Scotland) for plasmids. We thank Toshiki Tsurimoto (Kyushu University, Fukuoka),

6 Tsutomu Katayama (Kyushu University, Fukuoka), and Hironori Kawakami (Sanyo-Onoda City

7 University, Sanyo-Onoda) for discussion and comment. We appreciate technical support from the

8 Research Support Center, Research Center for Human Disease Modeling, Kyushu University Graduate

9 School of Medical Sciences. This investigation was supported, in part, by a grant to KY from the

10 Japan Society for the Promotion of Science (KAKENHI grant number JP17K15065). MH was

11 supported by a JSPS research fellowship (JP18J11443).

\section{Author contributions:}

$14 \mathrm{KY}$ and MF designed and managed the project. MH, YM, JY and KY conducted the experiments

15 and data analysis. NS and MF supervised the experiments and data analysis. MH, KY, and MF

16 wrote the manuscript.

18 Conflict of interest:

19 The authors declare that no competing interests exist. 


\section{References}

Alver RC, Chadha GS, Blow JJ. 2014. The contribution of dormant origins to genome stability: From cell biology to human genetics. DNA Repair (Amst) 19:182-189. doi:10.1016/j.dnarep.2014.03.012

Atanasiu C, Deng Z, Wiedmer A, Norseen J, Lieberman PM. 2006. ORC binding to TRF2 stimulates OriP replication. EMBO Rep 7:716-721. doi:10.1038/sj.embor.7400730

Beck DB, Burton A, Oda H, Ziegler-Birling C, Torres-Padilla ME, Reinberg D. 2012. The role of PR-Set7 in replication licensing depends on Suv4-20h. Genes Dev 26:2580-2589. doi:10.1101/gad.195636.112

Bicknell LS, Bongers EMHF, Leitch A, Brown S, Schoots J, Harley ME, Aftimos S, Al-Aama JY, Bober M, Brown PAJ, Van Bokhoven H, Dean J, Edrees AY, Feingold M, Fryer A, Hoefsloot LH, Kau N, Knoers

Bleichert F. 2019. Mechanisms of replication origin licensing: a structural perspective. Curr Opin Struct Biol NVAM, MacKenzie J, Opitz JM, Sarda P, Ross A, Temple IK, Toutain A, Wise CA, Wright M, Jackson AP. 2011. Mutations in the pre-replication complex cause Meier-Gorlin syndrome. Nat Genet 43:356360. doi:10.1038/ng.775

Celli GB, de Lange T. 2005. DNA processing is not required for ATM-mediated telomere damage response 59:195-204. doi:10.1016/j.sbi.2019.08.007

Bleichert F, Leitner A, Aebersold R, Botchan MR, Berger JM. 2018. Conformational control and DNAbinding mechanism of the metazoan origin recognition complex. Proc Natl Acad Sci U S A 115:E5906E5915. doi:10.1073/pnas.1806315115

Cawthon RM. 2002. Telomere measurement by quantitative PCR. Nucleic Acids Res 30:e47. doi:10.1093/nar/30.10.e47

Chan KL, Palmai-Pallag T, Ying S, Hickson ID. 2009. Replication stress induces sister-chromatid bridging at fragile site loci in mitosis. Nat Cell Biol 11:753-760. doi:10.1038/ncb1882

Chen Y, Rai R, Zhou ZR, Kanoh J, Ribeyre C, Yang Y, Zheng H, Damay P, Wang F, Tsujii H, Hiraoka Y, Shore D, Hu HY, Chang S, Lei M. 2011. A conserved motif within RAP1 has diversified roles in

Chen Y, Yang Y, van Overbeek M, Donigian JR, Baciu P, de Lange T, Lei M. 2008. A shared docking motif in TRF1 and TRF2 used for differential recruitment of telomeric proteins. Science 319:1092-1096. doi:10.1126/science. 1151804

31 Chuang CH, Wallace MD, Abratte C, Southard T, Schimenti JC. 2010. Incremental genetic perturbations to 
MCM2-7 expression and subcellular distribution reveal exquisite sensitivity of mice to DNA replication stress. PLoS Genet 6:e1001110. doi:10.1371/journal.pgen.1001110

d'Adda di Fagagna F, Reaper PM, Clay-Farrace L, Fiegler H, Carr P, Von Zglinicki T, Saretzki G, Carter NP, Jackson SP. 2003. A DNA damage checkpoint response in telomere-initiated senescence. Nature 426:194-198. doi:10.1038/nature02118

de Lange T. 2018. Shelterin-Mediated Telomere Protection. Annu Rev Genet 52:223-247. doi:10.1146/annurev-genet-032918-021921

Dellino GI, Cittaro D, Piccioni R, Luzi L, Banfi S, Segalla S, Cesaroni M, Mendoza-Maldonado R, Giacca M, Pelicci PG. 2013. Genome-wide mapping of human DNA-replication origins: Levels of transcription at ORC1 sites regulate origin selection and replication timing. Genome Res 23:1-11. doi:10.1101/gr.142331.112

Deng Z, Dheekollu J, Broccoli D, Dutta A, Lieberman PM. 2007. The Origin Recognition Complex Localizes to Telomere Repeats and Prevents Telomere-Circle Formation. Curr Biol 17:1989-1995. doi:10.1016/j.cub.2007.10.054

Drosopoulos WC, Deng Z, Twayana S, Kosiyatrakul ST, Vladimirova O, Lieberman PM, Schildkraut CL. 2020. TRF2 Mediates Replication Initiation within Human Telomeres to Prevent Telomere Dysfunction. Cell Rep 33:108379. doi:10.1016/j.celrep.2020.108379

Drosopoulos WC, Kosiyatrakul ST, Schildkraut CL. 2015. BLM helicase facilitates telomere replication during leading strand synthesis of telomeres. J Cell Biol 210:191-208. doi:10.1083/jcb.201410061

Drosopoulos WC, Kosiyatrakul ST, Yan Z, Calderano SG, Schildkraut CL. 2012. Human telomeres replicate using chromosomespecific, rather than universal, replication programs. J Cell Biol 197:253-266. doi:10.1083/jcb.201112083

Fouché N, Özgür S, Roy D, Griffith JD. 2006. Replication fork regression in repetitive DNAs. Nucleic Acids Res 34:6044-6050. doi:10.1093/nar/gk1757

Fujita M. 2006. Cdt1 revisited: Complex and tight regulation during the cell cycle and consequences of deregulation in mammalian cells. Cell Div 1:22. doi:10.1186/1747-1028-1-22

Fujita M, Ishimi Y, Nakamura H, Kiyono T, Tsurumi T. 2002. Nuclear organization of DNA replication initiation proteins in mammalian cells. J Biol Chem 277:10354-10361. doi:10.1074/jbc.M111398200

Giacca M, Zentilin L, Norio P, Diviacco S, Dimitrova D, Contreas G, Biamonti G, Perini G, Weighardt F, Riva S, Falaschi A. 1994. Fine mapping of a replication origin of human DNA. Proc Natl Acad Sci US A 91:7119-7123. doi:10.1073/pnas.91.15.7119 
Gilson E, Géli V. 2007. How telomeres are replicated. Nat Rev Mol Cell Biol 8:825-838. doi: $10.1038 / \mathrm{nrm} 2259$

Guervilly JH, Gaillard PH. 2018. SLX4: multitasking to maintain genome stability. Crit Rev Biochem Mol Biol 53:475-514. doi:10.1080/10409238.2018.1488803

Higa M, Fujita M, Yoshida K. 2017a. DNA replication origins and fork progression at mammalian telomeres. Genes (Basel) 8:112. doi:10.3390/genes8040112

Higa M, Kushiyama T, Kurashige S, Kohmon D, Enokitani K, Iwahori S, Sugimoto N, Yoshida K, Fujita M. 2017b. TRF2 recruits ORC through TRFH domain dimerization. Biochim Biophys Acta - Mol Cell Res 1864:191-201. doi:10.1016/j.bbamcr.2016.11.004

Hills SA, Diffley JFX. 2014. DNA Replication and Oncogene-Induced Replicative Stress. Curr Biol 24:R435-R444. doi:10.1016/j.cub.2014.04.012

Hoshina S, Yura K, Teranishi H, Kiyasu N, Tominaga A, Kadoma H, Nakatsuka A, Kunichika T, Obuse C, Waga S. 2013. Human origin recognition complex binds preferentially to G-quadruplex-preferable RNA and single-stranded DNA. J Biol Chem 288:30161-30171. doi:10.1074/jbc.M113.492504

Janicki SM, Tsukamoto T, Salghetti SE, Tansey WP, Sachidanandam R, Prasanth K V., Ried T, Shav-Tal Y,

Ibarra A, Schwob E, Méndez J. 2008. Excess MCM proteins protect human cells from replicative stress by licensing backup origins of replication. Proc Natl Acad Sci U S A 105:8956-8961. doi:10.1073/pnas.0803978105

Ishimoto R, Tsuzuki Y, Matsumura T, Kurashige S, Enokitani K, Narimatsu K, Higa M, Sugimoto N, Yoshida K, Fujita M. 2021. SLX4-XPF mediates DNA damage responses to replication stress induced by DNA-protein interactions. J Cell Biol 220:e202003148. doi:10.1083/jcb.202003148 Bertrand E, Singer RH, Spector DL. 2004. From silencing to gene expression: Real-time analysis in single cells. Cell 116:683-698. doi:10.1016/S0092-8674(04)00171-0

Kawabata T, Luebben SW, Yamaguchi S, Ilves I, Matise I, Buske T, Botchan MR, Shima N. 2011. Stalled Fork Rescue via Dormant Replication Origins in Unchallenged S Phase Promotes Proper Chromosome Segregation and Tumor Suppression. Mol Cell 41:543-553. doi:10.1016/j.molcel.2011.02.006

Kunnev D, Rusiniak ME, Kudla A, Freeland A, Cady GK, Pruitt SC. 2010. DNA damage response and tumorigenesis in Mcm2-deficient mice. Oncogene 29:3630-3638. doi:10.1038/onc.2010.125

Kuo AJ, Song J, Cheung P, Ishibe-Murakami S, Yamazoe S, Chen JK, Patel DJ, Gozani O. 2012. The BAH domain of ORC1 links H4K20me2 to DNA replication licensing and Meier-Gorlin syndrome. Nature 484:115-119. doi:10.1038/nature10956 
Li B, Oestreich S, Lange T De. 2000. Identification of Human Rap1 : Implications for Telomere Evolution. Cell 101:471-483.

Li N, Lam WH, Zhai Y, Cheng J, Cheng E, Zhao Y, Gao N, Tye BK. 2018. Structure of the origin recognition complex bound to DNA replication origin. Nature 559:217-222. doi:10.1038/s41586-018-0293-x

Lindberg HK, Falck GCM, Järventaus H, Norppa H. 2008. Characterization of chromosomes and chromosomal fragments in human lymphocyte micronuclei by telomeric and centromeric FISH. Mutagenesis 23:371-376. doi:10.1093/mutage/gen027

Martínez P, Blasco MA. 2015. Replicating through telomeres: A means to an end. Trends Biochem Sci 40:504-515. doi:10.1016/j.tibs.2015.06.003

Martínez P, Thanasoula M, Muñoz P, Liao C, Tejera A, McNees C, Flores JM, Fernández-Capetillo O, Tarsounas M, Blasco MA. 2009. Increased telomere fragility and fusions resulting from TRF1 deficiency lead to degenerative pathologies and increased cancer in mice. Genes Dev 23:2060-2075. doi:10.1101/gad.543509

McNairn AJ, Chuang CH, Bloom JC, Wallace MD, Schimenti JC. 2019. Female-biased embryonic death from inflammation induced by genomic instability. Nature 567:105-108. doi:10.1038/s41586-019-0936-6

Mendez-Bermudez A, Lototska L, Bauwens S, Giraud-Panis MJ, Croce O, Jamet K, Irizar A, Mowinckel M, Koundrioukoff S, Nottet N, Almouzni G, Teulade-Fichou MP, Schertzer M, Perderiset M, LondoñoVallejo A, Debatisse M, Gilson E, Ye J. 2018. Genome-wide Control of Heterochromatin Replication by the Telomere Capping Protein TRF2. Mol Cell 70:449-461. doi:10.1016/j.molcel.2018.03.036

Miotto B, Ji Z, Struhl K. 2016. Selectivity of ORC binding sites and the relation to replication timing, fragile sites, and deletions in cancers. Proc Natl Acad Sci U S A 113:E4810-9. doi:10.1073/pnas.1609060113

Moreno A, Carrington JT, Albergante L, Mamun M Al, Haagensen EJ, Komseli ES, Gorgoulis VG, Newman TJ, Blow JJ. 2016. Unreplicated DNA remaining from unperturbed $S$ phases passes through mitosis for resolution in daughter cells. Proc Natl Acad Sci U S A 113:E5757-E5764. doi:10.1073/pnas.1603252113

Muñoz IM, Hain K, Déclais AC, Gardiner M, Toh GW, Sanchez-Pulido L, Heuckmann JM, Toth R, Macartney T, Eppink B, Kanaar R, Ponting CP, Lilley DMJ, Rouse J. 2009. Coordination of StructureSpecific Nucleases by Human SLX4/BTBD12 Is Required for DNA Repair. Mol Cell 35:116-127. doi:10.1016/j.molcel.2009.06.020

Okumura M, Natsume T, Kanemaki MT, Kiyomitsu T. 2018. Dynein-dynactin-NuMA clusters generate cortical spindle-pulling forces as a multiarm ensemble. Elife 7:e36559. doi:10.7554/eLife.36559

Panier S, Boulton SJ. 2014. Double-strand break repair: 53BP1 comes into focus. Nat Rev Mol Cell Biol 15:7- 
18. doi:10.1038/nrm3719

Parker MW, Bell M, Mir M, Kao JA, Darzacq X, Botchan MR, Berger JM. 2019. A new class of disordered elements controls DNA replication through initiator self-assembly. Elife 8:e48562. doi:10.7554/eLife.48562

Parker MW, Botchan MR, Berger JM. 2017. Mechanisms and regulation of DNA replication initiation in eukaryotes. Crit Rev Biochem Mol Biol 52:107-144. doi:10.1080/10409238.2016.1274717

Pfeiffer V, Lingner J. 2013. Replication of telomeres and the regulation of telomerase. Cold Spring Harb Perspect Biol 5:a010405. doi:10.1101/cshperspect.a010405

Picard F, Cadoret JC, Audit B, Arneodo A, Alberti A, Battail C, Duret L, Prioleau MN. 2014. The Spatiotemporal Program of DNA Replication Is Associated with Specific Combinations of Chromatin Marks in Human Cells. PLoS Genet 10. doi:10.1371/journal.pgen.1004282

Poulet A, Buisson R, Faivre-Moskalenko C, Koelblen M, Amiard S, Montel F, Cuesta-Lopez S, Bornet O, Guerlesquin F, Godet T, Moukhtar J, Argoul F, Déclais AC, Lilley DMJ, Ip SCY, West SC, Gilson E, Giraud-Panis MJ. 2009. TRF2 promotes, remodels and protects telomeric Holliday junctions. EMBO J 28:641-651. doi:10.1038/emboj.2009.11

Rai R, Chen Y, Lei M, Chang S. 2016. TRF2-RAP1 is required to protect telomeres from engaging in homologous recombination-mediated deletions and fusions. Nat Commun 7:10881.

\section{doi:10.1038/ncomms10881}

Ran FA, Hsu PD, Wright J, Agarwala V, Scott DA, Zhang F. 2013. Genome engineering using the CRISPRCas9 system. Nat Protoc 8:2281-2308. doi:10.1038/nprot.2013.143

Saint-Léger A, Koelblen M, Civitelli L, Bah A, Djerbi N, Giraud-Panis MJ, Londonõ-Vallejo A, Ascenzioni F, Gilson E. 2014. The basic N-terminal domain of TRF2 limits recombination endonuclease action at human telomeres. Cell Cycle 13:2469-2474. doi:10.4161/cc.29422

Sarek G, Kotsantis P, Ruis P, Van Ly D, Margalef P, Borel V, Zheng XF, Flynn HR, Snijders AP, Chowdhury D, Cesare AJ, Boulton SJ. 2019. CDK phosphorylation of TRF2 controls t-loop dynamics during the cell cycle. Nature 575:523-527. doi:10.1038/s41586-019-1744-8

Sarek G, Vannier J, Panier S, Petrini JHJ, Boulton SJ. 2015. TRF2 Recruits RTEL1 to Telomeres in S Phase to Promote T-Loop Unwinding. Mol Cell 57:622-635. doi:10.1016/j.molcel.2014.12.024

Sedlackova H, Rask MB, Gupta R, Choudhary C, Somyajit K, Lukas J. 2020. Equilibrium between nascent and parental MCM proteins protects replicating genomes. Nature 587:297-302. doi:10.1038/s41586020-2842-3 
Sfeir A, Kabir S, van Overbeek M, Celli GB, de Lange T. 2010. Loss of Rap1 Induces Telomere Recombination in the Absence of NHEJ or a DNA damage Signal. Science 327:1657-1661.

Sfeir A, Kosiyatrakul ST, Hockemeyer D, MacRae SL, Karlseder J, Schildkraut CL, de Lange T. 2009. Mammalian Telomeres Resemble Fragile Sites and Require TRF1 for Efficient Replication. Cell 138:90-103. doi:10.1016/j.cell.2009.06.021

Shima N, Alcaraz A, Liachko I, Buske TR, Andrews CA, Munroe RJ, Hartford SA, Tye BK, Schimenti JC. 2007. A viable allele of $\mathrm{Mcm} 4$ causes chromosome instability and mammary adenocarcinomas in mice. Nat Genet 39:93-98. doi:10.1038/ng1936

Stroik S, Hendrickson EA. 2020. Telomere replication-When the going gets tough. DNA Repair (Amst) 94:102875. doi:10.1016/j.dnarep.2020.102875

Sugimoto N, Fujita M. 2017. Molecular mechanism for chromatin regulation during MCM loading in mammalian cellsAdvances in Experimental Medicine and Biology. pp. 61-78. doi:10.1007/978-981-106955-0_3

Sugimoto N, Kitabayashi I, Osano S, Tatsumi Y, Yugawa T, Narisawa-Saito M, Matsukage A, Kiyono T, Fujita M. 2008. Identification of novel human Cdt1-binding proteins by a proteomics approach: Proteolytic regulation by APC/CCdh1. Mol Biol Cell 19:1007-1021. doi:10.1091/mbc.E07-09-0859

Sugimoto N, Maehara K, Yoshida K, Yasukouchi S, Osano S, Watanabe S, Aizawa M, Yugawa T, Kiyono T, Kurumizaka H, Ohkawa Y, Fujita M. 2015. Cdt1-binding protein GRWD1 is a novel histone-binding protein that facilitates MCM loading through its influence on chromatin architecture. Nucleic Acids Res 43:5898-5911. doi:10.1093/nar/gkv509

Sugimoto N, Yoshida K, Tatsumi Y, Yugawa T, Narisawa-Saito M, Waga S, Kiyono T, Fujita M. 2009. Redundant and differential regulation of multiple licensing factors ensures prevention of re-replication in normal human cells. J Cell Sci 122:1184-1191. doi:10.1242/jcs.041889

Sugimoto N, Yugawa T, Iizuka M, Kiyono T, Fujita M. 2011. Chromatin remodeler sucrose nonfermenting 2 homolog $(\mathrm{SNF} 2 \mathrm{H})$ is recruited onto DNA replication origins through interaction with Cdc10 proteindependent transcript 1 (Cdt1) and promotes pre-replication complex formation. J Biol Chem 286:3920039210. doi:10.1074/jbc.M111.256123

Takai H, Smogorzewska A, De Lange T. 2003. DNA damage foci at dysfunctional telomeres. Curr Biol 13:1549-1556. doi:10.1016/S0960-9822(03)00542-6

Tatsumi Y, Ezura K, Yoshida K, Yugawa T, Narisawa-Saito M, Kiyono T, Ohta S, Obuse C, Fujita M. 2008. Involvement of human ORC and TRF2 in pre-replication complex assembly at telomeres. Genes to Cells 13:1045-1059. doi:10.1111/j.1365-2443.2008.01224.x 
Tatsumi Y, Ohta S, Kimura H, Tsurimoto T, Obuse C. 2003. The ORC1 cycle in human cells: I. Cell cycleregulated oscillation of human ORC1. J Biol Chem 278:41528-41534. doi:10.1074/jbc.M307534200

Tocilj A, On KF, Yuan Z, Sun J, Elkayam E, Li H, Stillman B, Joshua-Tor L. 2017. Structure of the active form of human origin recognition complex and its ATPase motor module. Elife 6:e20818. doi:10.7554/eLife.20818.001

Van Ly D, Low RRJ, Frölich S, Bartolec TK, Kafer GR, Pickett HA, Gaus K, Cesare AJ. 2018. Telomere Loop Dynamics in Chromosome End Protection. Mol Cell 71:510-525. doi:10.1016/j.molcel.2018.06.025

van Overbeek M, de Lange T. 2006. Apollo, an Artemis-Related Nuclease, Interacts with TRF2 and Protects Human Telomeres in S Phase. Curr Biol 16:1295-1302. doi:10.1016/j.cub.2006.05.022

van Steensel B, Smogorzewska A, de Lange T. 1998. TRF2 protects human telomeres from end-to-end fusions. Cell 92:401-413. doi:10.1016/S0092-8674(00)80932-0

Vannier JB, Pavicic-Kaltenbrunner V, Petalcorin MIR, Ding H, Boulton SJ. 2012. RTEL1 dismantles T loops and counteracts telomeric G4-DNA to maintain telomere integrity. Cell 149:795-806.

$$
\text { doi:10.1016/j.cell.2012.03.030 }
$$

Wan B, Yin J, Horvath K, Sarkar J, Chen Y, Wu J, Wan K, Lu J, Gu P, Yu EY, Lue NF, Chang S, Liu Y, Lei M. 2013. SLX4 Assembles a Telomere Maintenance Toolkit by Bridging Multiple Endonucleases with Telomeres. Cell Rep 4:861-869. doi:10.1016/j.celrep.2013.08.017

Wang RC, Smogorzewska A, De Lange T. 2004. Homologous recombination generates t-loop-sized deletions at human telomeres. Cell 119:355-368. doi:10.1016/j.cell.2004.10.011

Ye J, Lenain C, Bauwens S, Rizzo A, Saint-Léger A, Poulet A, Benarroch D, Magdinier F, Morere J, Amiard S, Verhoeyen E, Britton S, Calsou P, Salles B, Bizard A, Nadal M, Salvati E, Sabatier L, Wu Y, Biroccio A, Londoño-Vallejo A, Giraud-Panis MJ, Gilson E. 2010. TRF2 and Apollo Cooperate with Topoisomerase $2 \alpha$ to Protect Human Telomeres from Replicative Damage. Cell 142:230-242. doi:10.1016/j.cell.2010.05.032

Ying S, Minocherhomji S, Chan KL, Palmai-Pallag T, Chu WK, Wass T, Mankouri HW, Liu Y, Hickson ID. 2013. MUS81 promotes common fragile site expression. Nat Cell Biol 15:1001-1007. doi:10.1038/ncb2773 